\title{
Advances in science
}

and risk assessment tools

for Vibrio parahaemolyticus

and $V$. vulnificus associated

with seafood
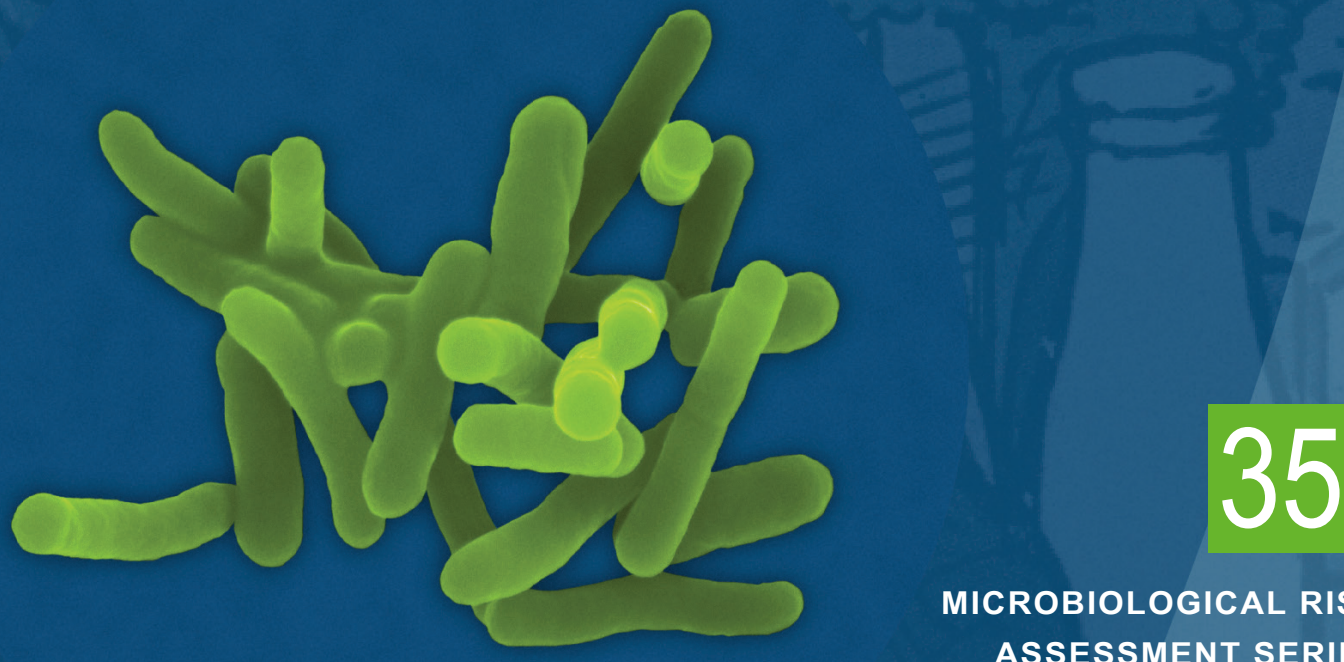

MICROBIOLOGICAL RISK ASSESSMENT SERIES 


\section{Advances in science}

\section{and risk assessment tools}

for Vibrio parahaemolyticus

and $V$. vulnificus associated

with seafood

\section{MEETING REPORT}


Required citation:

FAO and WHO. 2021. Advances in science and risk assessment tools for Vibrio parahaemolyticus and V. vulnificus associated with seafood. Meeting report. Microbiological Risk Assessment Series No. 35. Rome. https://doi.org/10.4060/cb5834en

The designations employed and the presentation of material in this information product do not imply the expression of any opinion whatsoever on the part of the Food and Agriculture Organization of the United Nations (FAO) or the World Health Organization (WHO) concerning the legal or development status of any country, territory, city or area or of its authorities, or concerning the delimitation of its frontiers or boundaries. The mention of specific companies or products of manufacturers, whether or not these have been patented, does not imply that these have been endorsed or recommended by FAO or WHO in preference to others of a similar nature that are not mentioned.

The views expressed in this information product are those of the author(s) and do not necessarily reflect the views or policies of FAO or WHO.

ISSN 1726-5274 [Print]

ISSN 1728-0605 [Online]

FAO ISBN 978-92-5-134739-3

WHO ISBN 978-92-4-002487-8 (electronic version)

WHO ISBN 978-92-4-002488-5 (print version)

(c) FAO and WHO, 2021

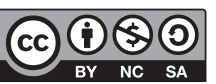

Some rights reserved. This work is made available under the Creative Commons AttributionNonCommercial-ShareAlike 3.0 IGO licence (CC BY-NC-SA 3.0 IGO; https://creativecommons.org/ licenses/by-nc-sa/3.0/igo/legalcode).

Under the terms of this licence, this work may be copied, redistributed and adapted for non-commercial purposes, provided that the work is appropriately cited. In any use of this work, there should be no suggestion that FAO or WHO endorses any specific organization, products or services. The use of the FAO or WHO logo is not permitted. If the work is adapted, then it must be licensed under the same or equivalent Creative Commons licence. If a translation of this work is created, it must include the following disclaimer along with the required citation: "This translation was not created by the Food and Agriculture Organization of the United Nations (FAO) or the World Health Organization (WHO). Neither FAO nor WHO is responsible for the content or accuracy of this translation. The original English edition shall be the authoritative edition."

Disputes arising under the licence that cannot be settled amicably will be resolved by mediation and arbitration as described in Article 8 of the licence except as otherwise provided herein. The applicable mediation rules will be the mediation rules of the World Intellectual Property Organization http:// www.wipo.int/amc/en/mediation/rules and any arbitration will be conducted in accordance with the Arbitration Rules of the United Nations Commission on International Trade Law (UNCITRAL).

Third-party materials. Users wishing to reuse material from this work that is attributed to a third party, such as tables, figures or images, are responsible for determining whether permission is needed for that reuse and for obtaining permission from the copyright holder. The risk of claims resulting from infringement of any third-party-owned component in the work rests solely with the user.

Sales, rights and licensing. FAO information products are available on the FAO website (www.fao. org/publications) and can be purchased through publications-sales@fao.org. Requests for commercial use should be submitted via: www.fao.org/contact-us/licence-request. Queries regarding rights and licensing should be submitted to: copyright@fao.org. 


\section{Contents}

Acknowledgements

Contributors

Declarations of interest

Abbreviations

Executive summary

\section{Introduction}

1.1 Background - pathogenic vibrios and seafood safety 2

$\begin{array}{lll}1.2 & \text { Vibrio parahaemolyticus } & 7\end{array}$

$\begin{array}{ll}1.3 \text { Vibrio vulnificus } & 9\end{array}$

1.4 Factors relevant to the fate of $V$. parahaemolyticus and $V$. vulnificus 12

Risk assessment for Vibrio spp. in seafood

2.1 Background to risk assessments in seafood $\quad 12$

2.22011 Risk assessment of V. parahaemolyticus in seafood 13

2.32005 Risk assessment of $V$. vulnificus in raw oysters 14

2.4 Recent FAO/WHO activities and expert meetings on vibrios $\quad 15$

New advances in vibrio science $\quad 16$

3.12019 FAO/WHO meeting 16

3.2 Recently available data 21

3.3 Newly available risk assessment models 25

3.4 Recommendations for best practice $\quad 27$

3.5 Microbiological testing methods 31

3.6 Climate change 36

$\begin{array}{ll}3.7 \text { Demographic drivers } & 38\end{array}$

Conclusions and recommendations $\quad 40$

$\begin{array}{ll}\text { References } & 43\end{array}$

ANNEXES

Annex 1 Selected available data on the incidence of V. parahaemolyticus infections in China 


\section{TABLES}

Table 1. Selected available data on the incidence of $V$. parahaemolyticus infections.

Table 2. Selected available data on the incidence of $V$. vulnificus infections in different countries.

Table 3. Currently available risk assessment models.

Table 4. Commonly used microbiological and molecular methods applied in the isolation and characterisation of Vibrio parhaemolyticus and Vibrio vulnificus.

Table 5. Climate suitability for vibrio outbreaks. Changes observed in the percentage of suitable areas from the 1980s to the present data.

\section{FIGURES}

Figure 1. Recent evolution of $V$. parahaemolyticus strain typing approaches.

Figure 2. Major microbiological, environmental and human-related factors responsible for driving vibriosis risks associated with bivalve shellfish. 


\section{Acknowledgements}

The Food and Agriculture Organization of the United Nations (FAO) and the World Health Organization (WHO) would like to express their appreciation to all those who contributed to the preparation of this report through the provision of their time and expertise, data and other relevant information before, during and after the meeting. Special appreciation is extended to all the members of the Expert Panel for their dedication to this project and to Dr Rachel Hartnell for her expert chairing of the Panel, and Craig Baker-Austin for his excellent support in preparing the final document. All contributors are listed in the following pages.

In addition, $\mathrm{FAO}$ and $\mathrm{WHO}$ would also like to appreciate those who contributed for the data collection, which includes: Annick Robert-Pillot and Marie-Laure Quilici, Institute Pasteur, France; Eckhard Strauch, Robert Koch Institute, Germany; Saara Salmenlinna, National Institute for Health and Welfare, Finland; Rodríguez Iglesias, Spain; Bo Pang, Chinese Center for Disease Control and Prevention, China; and Ronnie Gavilan, National Institute of Health, Peru.

The preparatory work and expert meeting convened to prepare this report was coordinated by the Secretariat of the Joint FAO/WHO Expert Meetings on Microbiological Risk Assessment (JEMRA).

We would like to pay our special gratitude and respect to Dr Mitsuaki Nishibuchi. After helping to discuss and initiate this meeting report, Dr Mitsuaki Nishibuchi passed away in June 2019. 


\section{Contributors}

\section{EXPERTS}

Carmen Amaro González, Universidad de Valencia, Spain

Enrico Buenaventura, Health Canada, Canada

Viviana Cachicas, Instituto de Sáalud Pública de Chile. (ISP-CH), Chile

Rachel Hartnell, FAO Reference Centre for Bivalve Mollusc Sanitation, Centre for Environment, Fisheries and Aquaculture Science (Cefas), the United Kingdom

Dominique Hervio-Heath, Institut Français de Recherche pour L'exploitation de la Mer (Ifremer), France

Dorothy Jean McCoubrey, Dorothy-Jean \& Associates Ltd, New Zealand

Iddya Karunasagar, Nitte University, India

Francesca Leoni, Istituto Zooprofilattico Sperimentale dell'Umbria e delle Marche “Togo Rosati” (IZSUM), Italy

Mitsuaki Nishibuchi, Kyoto University, Japan

Erin Stokes, Centers for Disease Control and Prevention (US CDC), the United States of America

\section{RESOURCE PERSONS}

Angelo DePaola, Angelo DePaola Consulting, LLC, the United States of America

Jaime Martinez-Urtaza, FAO Reference Centre for Bivalve Mollusc Sanitation, Centre for Environment, Fisheries and Aquaculture Science (Cefas), the United Kingdom

James D. Oliver, The University of North Carolina at Charlotte, the United States of America

\section{SECRETARIAT}

Craig Baker-Austin, FAO Reference Centre for Bivalve Mollusc Sanitation in Centre for Environment, Fisheries and Aquaculture Science (Cefas), the United Kingdom

Haruka Igarashi, Department of Nutrition and Food Safety, World Health Organization, Switzerland

Jeffrey LeJeune, Food Systems and Food Safety Division, Food and Agriculture Organization of the United Nations, Italy

Satoko Murakami, Department of Nutrition and Food Safety, World Health Organization, Switzerland

Kang Zhou, Food Systems and Food Safety Division, Food and Agriculture Organization of the United Nations, Italy 


\section{Declarations of interest}

All participants completed a Declaration of interests form in advance of their involvement in in this work.

Two of the Experts declared interest in the topic under consideration.

Angelo DePaola and James D. Oliver declared that they had consulting income. Upon detailed review of the declaration, it was considered that the activities of Angelo DePaola and James D. Oliver represent a potential conflict of interest. Therefore, they were invited to the meeting, but did not participate in the final adoption of the conclusions and recommendations of the meeting.

All of the declarations, together with any updates, were made known and available to all the participants at the beginning of the meeting.

All the Experts participated in their individual capacities and not as representatives of their countries, governments or organizations. 


\title{
Abbreviations
}

\author{
${ }^{\circ} \mathrm{C} \quad$ Degree Celsius \\ APPCR Arbitrarily primed polymerase chain reaction \\ CDC Centers for Disease Control and Prevention \\ Cefas Centre for Environment, Fisheries and Aquaculture Science \\ CCFH Codex Committee on Food Hygiene \\ COVIS Cholera and Other Vibrio Illness Surveillance \\ FAO Food and Agriculture Organization of the United Nations \\ FDA Food and Drug Administration of the United States of America \\ HPP High pressure processing \\ IQF Individual quick freezing \\ ISO International Organization for Standardization \\ JEMRA Joint FAO/WHO expert meetings on microbiological risk assessment \\ kGy Kilogray \\ ILSI International Life Science Institute \\ L Litre \\ LAMP Loop-mediated isothermal amplification \\ LOD Limit of detection \\ MLST Multi-locus sequence typing \\ Mpa MegaPascal \\ MPN Most probable number \\ NSSP National shellfish sanitation programme \\ PBS Phosphate Buffered Saline \\ PCR Polymerase chain reaction \\ PFGE Pulsed field gel electrophoresis \\ PNW Pacific Northwest \\ Ppt Parts per thousand \\ PSU Practical salinity units \\ qPCR Quantitative polymerase chain reaction \\ RS Remote sensing \\ SNP Single nucleotide polymorphism \\ SST Sea surface temperature \\ ST3 Sequence type 3 \\ ST36 Sequence type 36 \\ TDH Thermostable direct hemolysin \\ TRH TDH-related hemolysin \\ T3SS Type III secretion system \\ USDA United States of America Department of Agriculture \\ USFDA United States of America Food and Drug Administration \\ VPRA V. parahaemolyticus risk assessment \\ VVRA V. vulnificus risk assessment \\ WGS Whole genome sequencing \\ WHO World Health Organization
}




\section{Executive summary}

Globally, the bacterial species V. parahaemolyticus, V. cholerae and V. vulnificus represent important human pathogens associated with the consumption of seafood. In response to the requests for scientific advice from Codex Committee on Food Hygiene (CCFH), risk assessments for the pathogens V. vulnificus, V. cholerae, $V$. parahaemolyticus and guidance on methods for the detection of Vibrio spp. in seafood have been conducted and published previously by FAO/WHO Joint Expert Meeting on Microbiological Risk Assessment (JEMRA) (e.g. the 2005 Risk assessment of V. vulnificus in raw oysters (VVRA) and the 2011 Risk assessment of V. parahaemolyticus in seafood (FAO/WHO, 2005a, 2011). In order to provide an update on the state-of-the-art advice regarding risk assessment for $V$. parahaemolyticus and V. vulnificus in seafood, an expert meeting was convened at Centre for Environment Fisheries and Aquaculture Science (Cefas), Weymouth, the United Kingdom, on 13-15 May 2019. This report is the output of that expert meeting.

Raw shellfish products such as oysters and clams are the most common foodborne source of vibriosis; thus this document outlines key areas where recent risk assessment has been carried out with regards to assessing, understanding and reducing potential human health risks in these food commodities. Experts reviewed the draft outputs of the expert meeting in 2010 on the risk assessment tools for $V$. parahaemolyticus and V. vulnificus associated with seafood. It was agreed that the basic information of pathogenicity (including virulence markers), major factors relevant to the fate of $V$. parahaemolyticus and V. vulnificus (water temperature and salinity) and other main contents had not changed substantially; however, several new models and methods have become available in the last decade which were worthy of inclusion. In addition, several new developments were discussed, including the emergence of highly pathogenic strains of $V$. parahaemolyticus, as well as the pandemic spread of associated infections which represented key challenges to the seafood industry, risk managers, clinicians and public health. The expert group considered a number of topics where significant new information had emerged in the last decade (and since the publication of the 2010 meeting workshop draft report). These included (1) recent epidemiological data, (2) approaches on remote sensing-based risk assessment models, (3) improvements to detection and molecular methods, (4) aspects related to best practice for reducing risk, (5) new information on climate change, and (6) demographics; all of which represented key aspects in terms of modulating human health risks associated with these pathogens.

Several critical developments in the last decade were subsequently noted by the expert working group: 1) The emergence of highly pathogenic strains, in particular 
the Pacific Northwest (PNW) V. parahaemolyticus strain (ST36), which have spread to the East coast of the United States of America, Europe, South America and New Zealand. The pandemic spread of these highly pathogenic strains is of global concern for seafood safety. 2) In response to climate change, there has been a significant geographical spread regarding where seafood-associated vibrio infections have been reported, with a general trend in the poleward spread of $V$. parahaemolyticus and V. vulnificus cases. Over the last decade in particular, there has been an increase in reported illnesses as well as the geographical spread of foodborne infections associated with these bacteria into regions where reported infections were previously absent. 3) The expert group noted that demographic considerations are also important. Globally, an increased at-risk population, increased population densities in coastal regions and improvements in diagnosis of infections may also have played a role in accentuating reported cases. 4) The expert group identified that a range of new approaches for best practice, such as highpressure treatment, harvesting curfews, relaying and temperature controls appear to offer effective and cost-effective approaches for reducing human health risks postharvest associated with these pathogens. Finally, 5) the expert group identified that a range of new methods, such as those utilising genomics and satellite imagery, provide novel means of complementing approaches outlined in previous risk assessment exercises for these globally important foodborne pathogens. The expert group noted, however, that a range of critical data gaps exist. These include approaches to infer further characterization of strains (for instance serotyping, MLST, genotyping, APPCR, WGS); virulence testing; gene expression levels; strain phylogeny and phylogeography. In particular, the paucity of high quality data from geographically diverse regions (other than the United States of America) probably represents the most pressing limitation for risk assessment efforts in this arena.

This work has been greatly facilitated by contributions from experts around the world, with expertise in microbiology, risk assessment, molecular biology, remote sensing, epidemiology and modelling among others. 


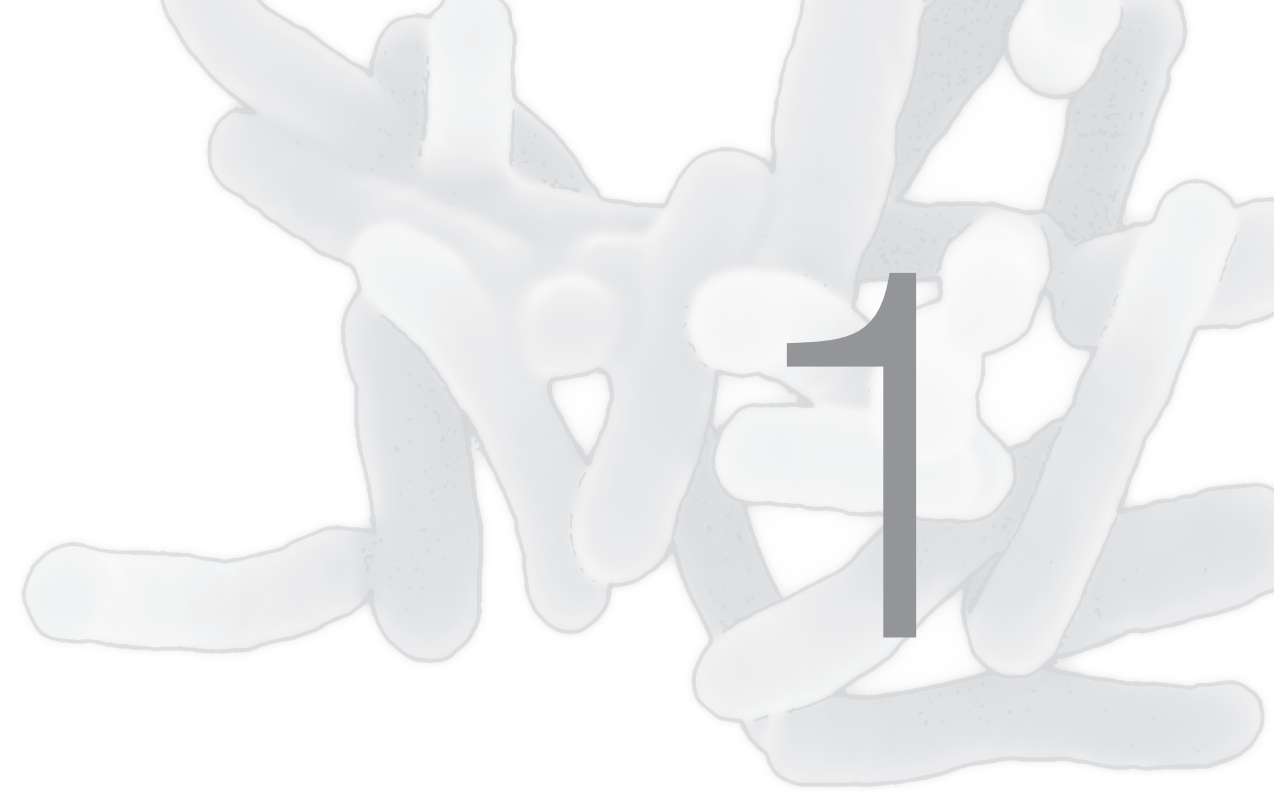

\section{Introduction}

\subsection{BACKGROUND - PATHOGENIC VIBRIOS AND SEAFOOD SAFETY}

Vibrio spp. are responsible for the majority of human diseases attributed to the natural flora of aquatic environments and seafood (Faruque and Nair, 2006). Vibrio spp. are a group of common, Gram-negative rod-shaped bacteria that are natural constituents of freshwater, estuarine and marine environments. Vibrio spp. represent a diverse group of human pathogens, and the disease manifestation and epidemiology associated with these bacteria is similarly complex (Baker-Austin et al., 2018). Seafood is part of healthy and balanced diet, yet this food commodity is responsible for a significant proportion of foodborne illnesses and outbreaks globally. Consumption of raw or insufficiently cooked seafood can result in human illness due to the presence of pathogenic microorganisms. Outbreaks of shellfishassociated infection have been reported for more than a century (Potasman et al., 2002). In particular, bivalve shellfish such as oysters, clams and mussels greatly concentrate bacteria present in the surrounding water. Various historical studies have shown that vibrio densities in oysters can exceed 100 times than that observed in water (DePaola et al., 1990). The accumulation of vibrios in seafood, and in particular bivalves, followed by consumption of that product either raw or not fully cooked is an established route of human exposure to these pathogens. Other contributing factors may include storage and transportation at inappropriate temperatures (e.g. outside of cold-chain), contamination by an infected food handler, or cross-contamination through contact with contaminated seafood or seawater (Iwamoto et al., 2010). There is a wealth of historical data implicating the pathogenic vibrios with the consumption of seafood, and in particular 
bivalve shellfish such as oysters, clams and mussels. Both V. vulnificus and $V$. parahaemolyticus have a longstanding history with seafood risk. Clinical strains associated with V. vulnificus were first isolated by the United States of America Centers for Disease Control and Prevention (CDC) in the mid to the 1960s (Hollis et al., 1976), whilst the first outbreak associated with $V$. parahaemolyticus was identified in 1950 in Japan (Fujino et al., 1953).

\subsection{VIBRIO PARAHAEMOLYTICUS}

Vibrio parahaemolyticus is a ubiquitous Gram-negative marine bacterium, and an inhabitant of temperate and tropical coastal areas around the world (BakerAustin et al., 2018). Globally, V. parahaemolyticus is the leading cause of bacterial gastroenteritis associated with the consumption of seafood products. An established route of transmission includes the consumption of raw bivalve shellfish species, such as oysters and clams; however cross contamination of seafood is another established route of human infections (Martinez-Urtaza et al., 2016). While the majority of environmental strains are innocuous members of the marine microbiota are opportunistic pathogens of humans (Johnson et al., 2008). Clinical characteristics of $V$. parahaemolyticus infections include abdominal cramps, diarrhoea, nausea, headaches, fever, and chills (Honda and Iida, 1993). Infections tend to be self-limiting, with the vast majority of cases not requiring medical interventions (Baker-Austin et al., 2018). The presence of V. parahaemolyticus in the marine environment is closely related to water temperature, with strains readily isolated when environmental temperatures exceed $15^{\circ} \mathrm{C}$ (Baker-Austin et al., 2010).

Clinical strains of $V$. parahaemolyticus isolated from ill patients tend to produce a variety of recognized virulence factors. Of these, the thermostable direct haemolysin (TDH) (Nishibuchi and Kaper, 1995), responsible for the Kanagawa haemolysis, and the TDH-related haemolysin (TRH) (Honda et al., 1988) are currently the most predictive overall indicators of potential virulence (Baker-Austin et al., 2018; Jones et al., 2012; Pazhana et al., 2014). Most infections are associated with strains that possess these genes, although there are notable published exceptions (Ottaviani et al., 2012). Detection of tdh-trh-strains among clinical strains has been the source of debate on the pathogenic roles of the $t d h+$ and/or the trh+ genes (FAO/WHO, 2020). Bhoopong et al. (2007) provided solid evidence for the possibility that has long been suspected among clinical microbiologists: the colonies on thiosulphate citrate bile salts sucrose agar (TCBS agar) that are derived from clinical samples may consists of virulent ( $t d h+$ and/or the $t r h+)$ and avirulent (tdh-trh-) strains of $V$. parahaemolyticus and accidental isolation of an avirulent (tdh-trh-) strain(s) is actually causing a misleading interpretation of the avirulent (tdh-trh-) strain(s) (FAO/WHO, 2020). Recently, type III secretion systems (T3SS), of which there are two types, have received attention. In particular, those located in the pathogenicity islands associated with the $t d h$ and trh genes are named T3SS2, 
and are considered to be possible virulence markers (Ceccarelli et al., 2019; Okada et al., 2009). Whole genome sequencing efforts have confirmed that pathogenic isolates of $V$. parahaemolyticus also encode two type III secretion systems (T3SS) (Makino et al., 2003; Richie et al., 2012; Okada et al., 2009) which are multiprotein structures that mediate the translocation of bacterial effector proteins directly into eukaryotic cells (Baker-Austin et al., 2018).

Until the late 1960 's $V$. parahaemolyticus cases were geographically restricted to Japan, but since 1969 infections have been reported from geographically diverse locations, including the Atlantic, Pacific and Gulf States and Hawaii in the United States of America. The geographical spread of these infections continued throughout the 1970s with sporadic cases and outbreaks reported in Europe, Africa, New Zealand and most of the Asian countries, thereby turning V.parahaemolyticus into a major seafood-borne pathogen and a global public health concern (Joseph et al., 1982; Baker-Austin et al., 2018). The epidemiology of $V$. parahaemolyticus is frequently characterized by sporadic cases of infection as well as large outbreaks in coastal areas, mostly associated with the consumption of raw or undercooked seafood over the summer months (Faruque and Nair, 2006). In the United States of America, Scallen et al. (2011) indicated that there are on average 34,664 infections each year caused by this bacterium (range 18,260-58,027 cases/year). Data from two independent epidemiological datasets in the United States of America (Cholera and Other Vibrio illness surveillance-COVIS and FoodNet) also indicated that $V$. parahaemolyticus infections were the most prevalent vibrio infections reported in the United States of America in the period 1996-2010, and represented the main pathogen associated with the consumption of seafood. (Newton et al., 2012; Anon 2020a, 2020b). Publications from the CDC using these datasets (Newton et al., 2012) have shown that there have been over recent years, a clear increase in $V$. parahaemolyticus infections in the United States of America. This study showed an increase in the incidence of $V$. parahaemolyticus in the United States of America between 1996 and 2010 with cases per 100,000 population raising from 0.01 to 0.13 (COVIS) and 0.06 to 0.23 (FoodNet). Of all bacterial foodborne diseases studied, data from CDC (FoodNet) indicated that vibriosis is the only disease group that has increased in incidence during the early 2000s (Anon, 2009). Although the Gulf Coast has historically been the region most frequently associated with $V$. parahaemolyticus infections, over recent years numerous reports have highlighted outbreaks occurring outside this region. These include outbreaks associated with oyster production in the Pacific Northwest in 1997 (Anon, 1998), Alaska in 2004, (McLaughlin et al., 2005) and more recently, and since the last risk assessment (FAO/WHO, 2011), a new clonal complex has emerged along the Eastern seaboard of the United States of America (Martinez-Urtaza et al., 2013; Newton et al., 2014). The strains that have emerged recently are termed "PNW" isolates ("Pacific Northwest"), and demonstrate enhanced pathogenicity compared to other pathogenic strains (Martinez-Urtaza et al., 2010). Recent studies have shown that PNW strains have been successfully introduced in the Northeast United States of 
America waters, and have become a prevalent source of infections in the Northeast United States of America (Martinez-Urtaza et al., 2017; Xu et al., 2017). Critically, shellfish-transmitted $V$. parahaemolyticus infections have recently increased in locations with historically low disease incidence, such as the Northeast United States of America. This change coincided with a bacterial population shift towards a greater proportion of human pathogenic variants occurring in the environment, in part because of the presence of several Pacific native lineages (ST36, ST43 and ST636) occurring in nearshore areas off the Atlantic coast of the Northeast United States of America (Xu et al., 2017). One of these instances was the result of the introduction of an unusual 'Pacific Northwest' complex clonal strains ("PNW" sequence type "ST36" strains) (Martinez-Urtaza et al., 2013). This same strain resulted in the 2012 V.parahaemolyticus outbreak in Spain associated with use of ice produced from local seawater contaminated with $V$. parahaemolyticus (MartinezUrtaza et al., 2016a). More recently, this ST36 strain was identified in Peru where it was associated with locally-acquired infections as well as in the environment, emphasizing the exceptional epidemic potential of the PNW complex (Abanto et al., 2020). ST36 strains have also emerged in New Zealand, again highlighting the rapid and pandemic expansion of these strains (New Zealand Ministry of Health, 2019). Elsewhere, V. parahaemolyticus infections have been reported across the entire globe, including largescale outbreaks in China, Chile, India, Japan and the Republic of Korea (Nair et al., 2007), mainly associated with the global spreading of the pandemic clone O3:K6 (ST3).

In contrast to Asian countries and the United States of America, non-cholera vibrio infections are less often reported in Europe (Baker-Austin et al., 2010). In Europe, reflecting the infrequency of identified cases, $V$. parahaemolyticus is not a notifiable illness and hence systematic epidemiological data are not available. However, a rise in $V$. parahaemolyticus cases has been identified in some "hotspots" of disease emergence. One of these regions is the northwest of Spain, where cases associated with V. parahaemolyticus have been reported since 1998. Global genome-wide phylogenetic analysis revealed that most of the pathogenic strains isolated from infections in Galicia were associated with globally diverse isolates, indicating frequent episodic emergence of these pathogens from disparate and remote sources. Examples of these introductions includes several instances of ST3 and one outbreak associated with the ST36, the two major epidemic clones of this pathogen (Martinez-Urtaza et al., 2018). Cases abruptly emerged in 1998 and infections were associated with large outbreaks caused by a single strain in 1999 (Lozano-León et al., 2003), 2004 (Martinez-Urtaza et al., 2005) and 2012 (Martinez-Urtaza et al., 2013). In 2015-2016, a shift in the epidemiological pattern associated with this disease was documented in this region, with the concurrent detection of cases scattered over the region linked to different and unrelated strains. These major switches in the epidemic dynamics of $V$. parahaemolyticus in the region have been associated with the increasing sea 
surface temperature trend experienced in coastal areas of northwest of Spain, which has been suggested as a fundamental contributing factor in the emergence of illness linked to these introduced pathogenic strains (Martinez-Urtaza et al., 2018). Similar to the situation in Spain, several domestic and travel-associated V. parahaemolyticus infections have been reported in the United Kingdom over the last 20 years (BakerAustin et al., 2019). A large genetic diversity of $V$. parahaemolyticus strains was observed, with ST3 (pandemic group) strains the most common sequence type. ST3 strains were also identified in environmental sources in the United Kingdom (Powell et al., 2013) which indicate the successful establishment in local environmental reservoirs. Several sporadic but noteworthy outbreaks have also been reported over the last 20 years in northern European countries. These include several cases involving seafood in Norway in 2011 as well as more recent sporadic infections in France and the United Kingdom (Baker-Austin et al., unpublished). Wound infections associated with these bacteria have also been reported with at least one fatality in Europe (BakerAustin et al., 2012). Elsewhere V.parahaemolyticus strains isolated during an outbreak of acute enteric disease in Vladivostok, the Russian Federation, in 1997 were identified as belonging to serotype O3:K6 (Smolikova et al., 2001).

Globally, one of the most important areas in terms of disease emergence over recent years is China, where V. parahaemolyticus has been the leading cause of foodborne outbreaks and bacterial infectious diarrhoea since the 1990s, especially in coastal regions (Lin et al., 2010; Liu et at., 2004). Between 2007-2012, V. parahaemolyticus was the dominant bacterial cause of acute diarrhoea in the southern coastal region of China, surpassing any other foodborne pathogen (Li et al., 2014). A total of 322 gastroenteritis outbreaks involving 9041 illnesses and 3948 hospitalizations due to V. parahaemolyticus infection were reported in China from 2003 to 2008 (Wu et al., 2014). Analysis of all the V. parahaemolyticus cases captured through surveillance established in Shenzhen City in the southern coastal region of China during 2007-2012 identified $1488 \mathrm{~V}$. parahaemolyticus infections over this period (Li et al., 2014). All these studies indicated the serotypes O3:K6 (ST3) and O4:K8 (ST88) as the most common among strains from clinical infections in China.

A reoccurring pattern of introduction of epidemic clones and disease emergence was also identified recently in Latin America. Several instances of introductions of epidemic clones have been documented in Peru over the last 30 years with infections emerging over the course of consecutive events of El Niño, which typically implies the incursions of warm oceanic waters along coastal areas of Peru coinciding with heavy rainfall events (Martinez-Urtaza et al., 2016b). Interestingly, these strains were identified previously in Asia, which supports the hypothesis a recurrent flow of strains from Asia to South America and the subsequent emergence of infections concurrently with the arrival of the warm conditions associated with El Niño.

TABLE 1. Selected available data on the incidence of $V$. parahaemolyticus infections. 


\begin{tabular}{|c|c|c|c|c|c|c|}
\hline $\begin{array}{l}\text { Country/ } \\
\text { Region }\end{array}$ & Period & $\begin{array}{l}\text { No. of cases } \\
\text { (outbreaks) }\end{array}$ & $\begin{array}{l}\text { Attributed } \\
\text { food }\end{array}$ & $\begin{array}{c}t d h / t r h \\
\text { presence } \\
\text { (where } \\
\text { reported) (\%) }\end{array}$ & Symptoms & Origin of data \\
\hline Canada & 2015 & 82 & Raw oysters & $\mathrm{N} / \mathrm{A}$ & N/A & $\begin{array}{l}\text { Public Health } \\
\text { Canada, 2020, } \\
\text { Taylor et al. } \\
2018\end{array}$ \\
\hline Canada & 2020 & 21 & Raw oysters & N/A & N/A & $\begin{array}{l}\text { Public Health } \\
\text { Canada, } 2020\end{array}$ \\
\hline Chile & $2011-2019$ & $\begin{array}{c}431 \text { (typically < } \\
100 \text { year) }\end{array}$ & Molluscs & $\begin{array}{c}\text { 9/35 cases } \\
\text { ST } 3(t d h+) \& \\
\text { 8/35 ST } 36 \\
(t d h+\& \text { trh }+)\end{array}$ & Diarrheal cases & $\begin{array}{l}\text { Abanto et al. } \\
2020\end{array}$ \\
\hline $\begin{array}{l}\text { China } \\
\text { (South) }^{a}\end{array}$ & $2010-2020$ & $\begin{array}{c}\text { Average } 313.5 \\
\text { cases, (19) }\end{array}$ & N/A & N/A & Diarrheal cases & $\begin{array}{l}\text { Data courtesy } \\
\text { Bo Pang } 2020 .\end{array}$ \\
\hline $\begin{array}{l}\text { China } \\
\text { (Central) }^{\mathrm{a}}\end{array}$ & $2010-2020$ & $\begin{array}{l}\text { Average } 61.4 \\
\text { cases, (6) }\end{array}$ & N/A & N/A & Diarrheal cases & $\begin{array}{l}\text { Data courtesy } \\
\text { Bo Pang } 2020 .\end{array}$ \\
\hline $\begin{array}{l}\text { China } \\
\text { (East) }^{\mathrm{a}}\end{array}$ & $2012-2020$ & $\begin{array}{c}\text { Average } 148.6 \\
\text { cases, }(13.6)\end{array}$ & N/A & N/A & Diarrheal cases & $\begin{array}{l}\text { Data courtesy } \\
\text { Bo Pang } 2020 .\end{array}$ \\
\hline $\begin{array}{l}\text { China } \\
\text { (South } \\
\text { West) }^{a}\end{array}$ & $2010-2020$ & Average 5.6 & N/A & N/A & Diarrheal cases & $\begin{array}{l}\text { Data courtesy } \\
\text { Bo Pang } 2020 .\end{array}$ \\
\hline England & $2010-2020$ & -22 cases $/ y r^{b}$ & $N / A$ & $\begin{array}{c}\text { tdh+ \& trh+, } \\
\text { tdh+, trh+ }\end{array}$ & Diarrheal cases & $\begin{array}{l}\text { Baker-Austin } \\
\text { et al. } 2020 .\end{array}$ \\
\hline Finland & $2010-2020$ & $11^{c}$ & N/A & N/A & N/A & $\begin{array}{l}\text { Data courtesy } \\
\text { Saara } \\
\text { Salmenlinna } \\
2020 \text {. }\end{array}$ \\
\hline France & 2010-2019 & 91 & Seafood & - & $\begin{array}{c}\text { Gastroenteritis } \\
(95 \%)\end{array}$ & $\begin{array}{l}\text { Data courtesy } \\
\text { Annick } \\
\text { Robert-Pillot, } \\
\text { Dominique } \\
\text { Hervio-Heath } \\
\text { \& Marie-Laure } \\
\text { Quilici } 2020\end{array}$ \\
\hline India & 2008-2011 & 29 & N/A & $\begin{array}{l}27 \text { tdh+ (five } \\
\text { were also } \\
\text { trh+), } 1 \text { trh+ }\end{array}$ & Diarrheal cases & $\begin{array}{l}\text { Guin et al. } \\
2019 .\end{array}$ \\
\hline Peru & 2015-2016 & $\sim 100$ & Seafood & $\begin{array}{c}100 \% t d h+\& \\
t r h+\end{array}$ & Diarrheal cases & $\begin{array}{l}\text { Caro-Castro et } \\
\text { al. } 2020 .\end{array}$ \\
\hline $\begin{array}{l}\text { Spain } \\
\text { (Cadiz) }\end{array}$ & $2010-2020$ & 7 cases & N/A & & $\begin{array}{l}\text { Diarrheal cases, } \\
\text { external otitis }\end{array}$ & $\begin{array}{l}\text { Data courtesy } \\
\text { Rodríguez } \\
\text { Iglesias } 2020 .\end{array}$ \\
\hline $\begin{array}{l}\text { Spain } \\
\text { (Galicia) }\end{array}$ & $2010-2020$ & $\begin{array}{l}69 \text { cases }(51 \\
10,2 \& 6)\end{array}$ & N/A & $\begin{array}{l}100 \% \text { tdh+ } \\
\& \text { trh+ from } \\
\text { outbreak } \\
\text { with } 6 \text { cases }\end{array}$ & $\begin{array}{l}\text { Diarrheal cases, } \\
\text { external otitis }\end{array}$ & $\begin{array}{l}\text { Martinez- } \\
\text { Urtaza et al. } \\
2016 .\end{array}$ \\
\hline $\begin{array}{l}\text { The United } \\
\text { States of } \\
\text { America }\end{array}$ & 2010-2018 & $4116^{d}$ & $\mathrm{~N} / \mathrm{A}$ & N/A & N/A & CDC, 2021. \\
\hline \multicolumn{7}{|l|}{$\begin{array}{l}\text { a Detail in annex } 1 . \\
\text { b Vast majority of } r \\
\text { c Includes both don } \\
\text { d Includes only case } \\
\text { on the reported c } \\
\text { N/A, not available. }\end{array}$} \\
\hline
\end{tabular}




\subsection{VIBRIO VULNIFICUS}

The Gram-negative bacterium $V$. vulnificus is a naturally occurring and common inhabitant of estuarine and coastal environments. This bacterium is a zoonotic agent linked to fish farms whose life cycle inside and outside its main hosts as well as its phylogeny have been recently reviewed by Hernández-Cabanyero and Amaro (2020). As a fish pathogen, this species causes outbreaks of a septicemic disease known as warm-water vibriosis (Amaro et al., 2015). As a human pathogen, this bacterium can infect either by consumption of raw seafood, in particular molluscan shellfish, or by contact of wounds with seawater or fish (mainly diseased fish) (Amaro et al., 2015; Ceccarelli et al., 2019). In the first case, the pathogen causes gastroenteritis or primary septicaemia and in the second case, severe wound infections and secondary septicaemia (Baker-Austin et al., 2018; Ceccarelli et al., 2019). Although some zoonotic cases after diseased fish handling have been described, $V$. vulnificus is mainly recognized as a significant foodborne pathogen since it is a leading cause of seafood-related mortality (Ceccarelli et al., 2019). The pathogen is present in high numbers in filtering organisms, such as oysters, especially in warmer months (Oliver et al., 2006). Vibrio vulnificus abundance and risk differs from that of $V$. parahaemolyticus as it prefers warmer and less saline conditions and is generally less widely distributed. Growth in oysters ceases below $13{ }^{\circ} \mathrm{C}$ and abundance plateaus above $25{ }^{\circ} \mathrm{C}$; illnesses are rarely associated with shellfish harvested from waters with temperatures below $20^{\circ} \mathrm{C}$. The VVRA found a broad salinity peak around $17 \mathrm{ppt}$ (5-25ppt) with typically non-detectable levels associated with negligible risk above 30ppt. Incidence of infection is related to environmental distribution, and $V$. vulnificus exhibits quite distinct temperature and salinity tolerances, being restricted to warm $\left(13-30^{\circ} \mathrm{C}\right)$ and low salinity (2-25ppt) waters (Hernández-Cabanyero and Amaro, 2020). Of some note, $V$. vulnificus-associated primary septicaemia carries the highest fatality rate of any studied foodborne pathogen (Rippey, 1994). The United States of America reported the mortality rate in cases of $V$. vulnificus infection due to shellfish consumption is approximately 53\% (Anon, 1993). Most cases of infection ( 95\%) occur in males. Vibrio vulnificus infections are characterised by a short incubation period between the onset of symptoms and subsequent clinical outcome (Baker-Austin et al., 2009; Baker-Austin and Oliver, 2018), typically within 24 hours of exposure (Jones and Oliver 2009). Numerous studies on the virulence factors involved in human vibriosis have been conducted. Of all the described virulence factors, those involved in sepsis, the capsule and the MARTX toxin (Multifunctional Autoprocessing Repeat in Toxin), also known as RtxA1, are the most relevant. The capsule protects against the bactericidal action of serum complement and phagocytosis (Carda-Dieguez et al., 2018) and the RtxAl toxin, in conjunction with hemolysin VvhA, promotes invasion from the intestine into the bloodstream 
(Jeong and Satchell, 2012) as well as the activation of an early blood cytokine storm (Murciano et al., 2016). Interestingly, the production of the capsule and the RtxA1 toxin are increased under iron excess, which could explain the rapid death from sepsis of patients with high levels of iron in their blood (Hernández-Cabanyero et al., 2019).

Several studies have utilised different molecular markers in $V$. vulnificus as a proxy for potential human virulence, with varying degrees of success. Differences in the sequence of the small subunit 16S rRNA gene, as correlating with either clinical (pathogenic) and environmental (non-pathogenic) origin, have been utilised previously (Aznar et al., 1994; Nilsson et al., 2003). More recently, an exploration of genes associated with virulence in humans focused on the virulence correlated gene ( $v c g$ ) (Rosche et al., 2005) and pilus-type IV-related gene pilF (Roig et al., 2010) which have both shown promise as molecular targets to identify virulent strains.

Vibrio vulnificus is a rare cause of infection $(\sim 100$ cases per year in the United States of America), but published studies demonstrate an increase in disease in the United States of America and also in Europe (Baker-Austin and Oliver, 2018). As with $V$. parahaemolyticus, the availability of both FoodNet and COVIS datasets in the United States of America helps to provide a highly useful national overview of disease burden associated with $V$. vulnificus. Using V. vulnificus data obtained from the CDC (COVIS) from recent collaborative work, the rate of infection has increased from 0.029 cases per 100000 of the population in 2007/2008 to 0.0502 in 2015/2016, an almost 2-fold increase in reported infections in less than a decade. However, most of the rise in infections have been attributable to wound infections, with shellfish-associated cases plateauing and, in some areas, reducing in incidence, particularly in the last two decades in the United States of America (Baker-Austin 2020, unpublished). Since 1988 when the CDC started to systematically record vibrio disease in the United States of America, there have been over $2600 \mathrm{~V}$. vulnificus cases nationally, with over 700 associated deaths, averaging around 30 fatalities a year which are predominantly from seafood sources. Overall, numbers of $V$. vulnificus cases have increased in the United States of America since 1988 (Baker-Austin et al., unpublished). Data published by the CDC (Newton et al., 2012) indicates increases in V. vulnificus infections reported in the United States of America between 1996 and 2010 in both the COVIS and FoodNet datasets, with a marked increase in the FoodNet data (0.01 infections per 100000 population in 1996, increasing to 0.05 cases per population in 2010). Globally, surveillance data regarding $V$. vulnificus infections are not gathered systematically, making wider geographical and epidemiological comparisons problematical (Table 2). In Europe, $V$. vulnificus infections are considered rare, and generally associated with 
bathing water exposure (Baker-Austin et al., 2012), with low salinity waters such as the Baltic Sea a hotspot for reported infections during heatwave events. A small number of seafood associated infections have occurred however, in Italy in the early 2000s and more recently in France (Baker-Austin et al., unpublished data). Where only fragmentary surveillance data exists (for example, published peer reviewed reports of infections) studies and available grey literature have shown infections reported in Europe, China, Uruguay, Japan and the Republic of Korea (Baker-Austin et al., 2018).

TABLE 2. Selected available data on the incidence of $V$. vulnificus infections in different countries.

\begin{tabular}{|c|c|c|c|c|}
\hline Country & Period & No. of cases & Symptoms & Origin of data \\
\hline England & 2011-2018 & $8^{*}$ & $N / A$ & $\begin{array}{l}\text { Public Health England } \\
\text { (PHE), } 2020\end{array}$ \\
\hline Finland & $2010-2020$ & $3^{* *}$ & $\mathrm{~N} / \mathrm{A}$ & $\begin{array}{l}\text { Data courtesy Saara } \\
\text { Salmenlinna } 2020 .\end{array}$ \\
\hline France & 2010-2019 & 10 & Wound infections & $\begin{array}{l}\text { Data courtesy } \\
\text { Annick Robert-Pillot, } \\
\text { Dominique } \\
\text { Hervio-Heath \& } \\
\text { Marie-Laure Quilici } \\
2020\end{array}$ \\
\hline Germany & 2002-2019 & $<20^{* * *}$ & $\mathrm{~N} / \mathrm{A}$ & $\begin{array}{l}\text { Robert Koch Institute, } \\
2020\end{array}$ \\
\hline $\begin{array}{l}\text { Spain } \\
\text { (Cadiz) }\end{array}$ & 2010-2016 & $\begin{array}{c}2 \\
(2011,2016)\end{array}$ & External otitis & $\begin{array}{l}\text { Data courtesy } \\
\text { Rodríguez Iglesias } \\
2020 \text {. }\end{array}$ \\
\hline $\begin{array}{l}\text { The United } \\
\text { States of } \\
\text { America }\end{array}$ & 2010-2018 & $245^{* * * *}$ & $\mathrm{~N} / \mathrm{A}$ & CDC, 2021. \\
\hline
\end{tabular}

*Vast majority of reported cases are derived from foreign-associated travel

**Includes both domestic and foreign-associated infections

***There was no mandatory reporting of vibrio infections before 2020. Increased numbers of infections apparent during heatwave years, such as 2003, 2006, 2010, 2018. 8 V. vulnificus cases were reported in Germany in 2020.

****Includes only cases reported to the Cholera and Other Vibrio Illness Surveillance (COVIS) System and classified as confirmed or probable foodborne illness based on the reported clinical specimen type and seafood consumption

\subsection{FACTORS RELEVANT TO THE FATE OF V. PARAHAEMOLYTICUS AND V. VULNIFICUS}

To more fully understand risks associated with $V$. vulnificus and $V$.parahaemolyticus it is necessary to understand factors that drive the abundance of these bacteria in raw/undercooked seafood. The most recent MRA document focusing on $V$. parahaemolyticus and $V$. vulnificus outlined a variety of factors that were deemed important with regards to modulating these risks. Risk models (outlined in section 2) draw heavily on factors that likely increase risk. Since the abundance of $V$. vulnificus and $V$. parahaemolyticus is a critical parameter to estimate the 
risk of infections, predictive models based on environmental variables were developed by FAO/WHO VPRA and VVRA that were validated by market data underpin V. parahaemolyticus and V. vulnificus Control Plans implemented by the Interstate Shellfish Sanitation Conference (ISSC) in 2007 and 2010, respectively. These tools estimate V. parahaemolyticus and V. vulnificus at harvest based on environmental studies that derived relationships between abundance with water temperature. Shellfish authorities employ these risk tools for scenario analysis of proposed controls to achieve mandated acceptable levels of risk. Inputs include water temperature to estimate concentrations of bacteria at the time of harvest, air temperatures for post-harvest growth rates, times to first refrigeration and time to reach no-growth temperatures. Outputs include abundance and risk per 100000 meals. Several factors have previously been outlined as critical in this regard:

Temperature. Seawater temperature has been reported as one of the principal environmental factors increasing the abundance of $V$. vulnificus and $V$. parahaemolyticus in many areas of the world (FAO/WHO, 2020). Their abundance in the natural environment tends to mirror ambient environmental temperatures (Baker-Austin et al., 2016; Pfeffer and Oliver 2003). Recent outbreaks associated with climatic anomalies, such as those observed in the NE United States of America (Newton et al., 2014), Spain (Martinez-Urtaza et al., 2013), and Chile (MartinezUrtaza et al., 2010), and non-cholera vibrio infections reported in Northern Europe during heatwave events (Baker-Austin et al., 2012; Baker-Austin et al., 2016) outline the importance of temperature in modulating risk (Baker-Austin et al., 2016). Recently, Hernandez-Cabanyero et al. (2020) demonstrated that warm temperatures (over $22^{\circ} \mathrm{C}$ ) activate adaptive traits that would prepare the bacteria for host colonization such as metabolism, motility, chemotaxis, protease activity, iron-uptake and production of $\mathrm{O}$-antigen of high molecular weight.

Salinity. Salinity has also been shown to play an important role in the survival and subsequent ecology of $V$. vulnificus and V.parahaemolyticus, and subsequently deemed critical to fully understand risk. Indeed, V. parahaemolyticus grows preferentially in warm $\left(>15^{\circ} \mathrm{C}\right)$, low-salinity marine waters $(<25 \mathrm{ppt} \mathrm{NaCl})$ (BakerAustin et al., 2010). Vibrio vulnificus occupies an ecological niche similar to Vibrio parahaemolyticus and its distribution is also governed by variations in salinity. $V$. vulnificus does not tolerate high salinity, and its distribution is mostly restricted to brackish water environments of temperate and tropical areas (Parvathi et al., 2004; Rivera et al., 1989). In areas of moderate salinity (from 1 to $25 \mathrm{ppt}$ ) and temperate or warm waters (e.g. Gulf of Mexico, Chesapeake Bay, the United States of America), seawater temperature is the major factor influencing the abundance. In areas with salinity close to oceanic waters (from 25 to $35 \mathrm{ppt}$ ) and temperate waters (e.g. Atlantic coasts of Europe), V. parahaemolyticus is detected during periods of lowest 
salinity, whereas seawater temperature influences the concentration. In tropical areas with minor changes in seawater temperature (e.g. India), no influence of salinity and temperature has been reported.

Other factors. In addition to seawater temperature and salinity, some additional abiotic and biotic factors have been identified modulating the presence and abundance of $V$. vulnificus and $V$. parahaemolyticus in coastal water around the world (FAO/WHO, 2020). Most studies have focussed on particular geographical areas; however additional factors such as chlorophyll A (Martinez-Urtaza et al., 2008; Urquhart et al., 2016; Oberbeckmann et al., 2012), nitrogen and carbon (Froelich et al., 2019), oceanic microplastics (Bowley et al., 2020), and the abundance of bacteriophages in the surrounding environment (Bastias et al., 2010) have been shown to modulate concentrations of vibrios. 


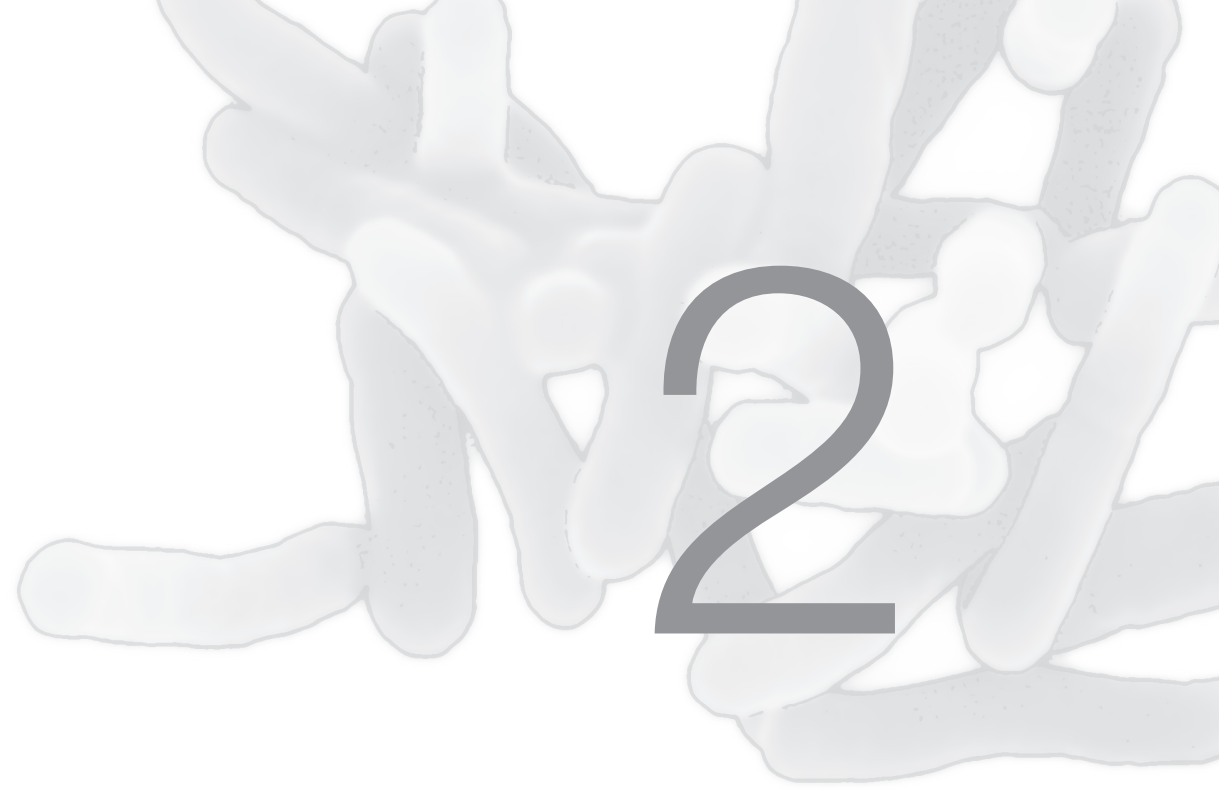

\section{Risk assessment for Vibrio spp. in seafood}

\subsection{BACKGROUND TO RISK ASSESSMENTS IN SEAFOOD}

The food safety concerns associated with vibrio pathogens has led to the need for microbiological risk assessments to support risk management practices. Previous FAO/WHO risk assessments regarding V. parahaemolyticus and $V$. vulnificus have been published (see below), and form the basis of international control measures frequently adopted to reduce risks from seafood. Previous expert consultation concluded that three species, V. parahaemolyticus, V. vulnificus, and choleragenic $V$. cholerae were the species responsible for most cases of human illness caused by vibrios, and several seafood vehicles associated with these illnesses were identified (FAO/WHO 2005). In $2001 \mathrm{FAO} / \mathrm{WHO}$ initiated a more comprehensive series of vibrio risk assessments and guidance, including:

- 2005: Risk assessment of $V$. vulnificus in raw oysters (FAO/WHO, 2005a)

- 2005: Risk assessment of choleragenic V. cholerae O1and O139 in warm water shrimp in international trade (FAO/WHO, 2005b)

- 2011: Risk assessment of V. parahaemolyticus in seafood (FAO/WHO, 2011)

- 2016: Selection and application of methods for the detection and enumeration of human pathogenic Vibrio spp. in seafood (FAO/WHO, 2016)

- 2020: Risk assessment tools for V. parahaemolyticus and $V$. vulnificus associated with seafoods (FAO/WHO, 2020)

A short overview of these risk assessments and their associated outcomes is outlined below. 


\subsection{RISK ASSESSMENT OF V. PARAHAEMOLYTICUS IN SEAFOOD}

Quantitative risk assessments have previously been developed for $V$. parahaemolyticus in oysters and followed the basic risk assessment structure outlined by Codex Alimentarius in their guidance for microbiological risk assessment: (1) hazard identification, (2) hazard characterization, (3) exposure assessment, and (4) risk characterisation (FAO/WHO, 2020). The $2011 \mathrm{~V}$. parahaemolyticus risk assessment used an oyster harvest public health model developed in one country (the United States of America) to assess risk in oysters from harvesting areas in other regions. The 2011 risk assessment work on $V$. parahaemolyticus in raw oysters used models developed during the United States of America Quantitative Risk Assessment on the Public Health Impact of Pathogenic V. parahaemolyticus in Raw Oysters (FDA VPRA) (FDA, 2005) to estimate risk of illness from this pathogen due to consumption of oysters in Australia, Canada, Japan and New Zealand. In short, that quantitative risk assessment used factors influencing the presence of V. parahaemolyticus in oysters and the flow of events that lead to human illnesses. The approach taken was applied to other products, such as the blood clam and finfish to determine to what extent such risk assessments could be adapted to other food commodities. When the FAO and WHO initiated the above risk assessments, most of the available data were generated in the United States of America. It was recognized early on that there were key regional differences even within the United States of America and the need to collect local data in order to calibrate predictions for accurate risk assessment purposes. Applying risk models based on data of the United States of America to other countries with different shellfish species and practices would increase uncertainty. However, a range of positive outcomes were established from the 2011 risk assessment work. The report represented an important body of knowledge regarding risk assessments for these globally important foodborne pathogens. Firstly, the model that was developed was successfully used to estimate illness from different oyster species grown under various regimes and regulatory management systems. Secondly, the framework of the model made available in the report could be modified and subsequently used by risk assessors in other countries. Finally, the model that was developed could be utilised as a useful tool for assessing and determining the efficacy of mitigation strategies, both at harvest (such as reduced cooling times) and postharvest by heating, freezing or highpressure treatment $(\mathrm{FAO} / \mathrm{WHO}, 2011)$. A range of key deficiencies in the data available to conduct the risk assessment were subsequently outlined in the report. These included a lack of data on the abundance of pathogenic V. parahaemolyticus in water and shellfish and the factors that drive the incidence of these bacteria in the environment; the role of oysters in concentrating and retaining these bacteria; the potential role of enterotoxin trh in driving infections; growth of pathogenic and non-pathogenic strains across a wider temperature range as well as the 
need for an improved global public health surveillance of $V$. parahaemolyticus to identify new epidemic strains as they emerge, and a greater clarity regarding the reporting systems used in each country of study - particularly with regards to underreporting of infections. The VPRA was useful in predicting exposure of total V. parahaemolyticus in the United States of America's oysters. However, flaws in two critical assumptions have emerged. The proportion of pathogenic strains $(t d h+)$ was estimated at $0.2 \%$ in Atlantic and Gulf regions and 3\% in Pacific areas; these have been found to vary up to near $100 \%$ temporally and geographically. More consequentially, all $t d h+$ strains were assumed to be equally virulent with an infectious dose $\left(\mathrm{LD}_{50}\right)$ between one and ten million $t d h+$ cells. An infection rate $>1$ 000-fold greater was observed in 2004 Alaska outbreak. Evidence of high infections rates have been reported for certain outbreak strains such as ST3 and ST36 (see section 1.2).

\subsection{RISK ASSESSMENT OF V. VULNIFICUS IN RAW OYSTERS}

Prior to the 2011 V. parahaemolyticus risk assessment, the pathogen V. vulnificus was chosen as a target to establish the first quantitative risk assessment for a vibrio pathogen in seafood. A major objective of the $V$. vulnificus risk assessment was to determine the usefulness of adapting the FDA VPRA and FAO/WHO VPRA models to assess the risk from $V$. vulnificus septicaemia associated with the consumption of raw oysters (determined to be the major route of foodborne human infections) (FAO/WHO, 2005a). A secondary objective of the V. vulnificus risk assessment aimed to identify the most appropriate data, as well as gaps in the available dataset, for modelling purposes (FAO/WHO, 2005a). An additional objective of this risk assessment was to determine potential mitigation strategies in reducing human infections (foodborne septicaemia). One key limitation to this risk assessment endeavour was noted from the outset: for reasons of data availability, the risk assessment was geographically limited to using data regarding primary septicaemia cases associated with consumption of raw oysters from the Gulf Coast of the United States of America. There is a paucity of data regarding primary septicaemia cases elsewhere (e.g. outside of the Gulf coast states of the United States of America). The risk assessment contained a number of key modules, including data derived from environmental sources (for instance water temperature at harvest, number of bacteria in oysters), key data on bacteria coupled to temperature postharvest, predicted numbers of bacteria in oysters at consumption, with dose response analysis coupled to the number of oyster servings and lastly an analysis of the risk of illness coupled to observed clinical infections. Several key conclusions were noted from this assessment. Firstly, a quantitative risk assessment could be successfully achieved for $V$. vulnificus by utilizing the framework and parameters for the $V$. parahaemolyticus 
risk assessment model. It was noted that where additional data were available it was possible to validate certain aspects of the risk assessment model (FAO/WHO, 2005a). Good agreement was noted between the exposure assessment predictions compared to retail study data used in the risk assessment. Because human volunteer data is not available for $V$. vulnificus (for obvious ethical reasons) even in the absence of such dose-response data it was possible to develop a correlative relationship from seasonal exposure predictions and the reported frequency of illness which was effective for risk characterization and the evaluation of interventions (FAO/WHO, 2005a). It was also noted that the model used for the $V$. vulnificus risk assessment provided a useful framework for other countries that required risk assessments on this pathogen, particularly in oysters. However, to be able to use the model outlined it was necessary to refine the approach using country-specific data, and to date this remains elusive, in particular on the abundance of $V$. vulnificus in seafood associated with primary septicaemia, at harvest and the point of consumption, as well as data on the susceptibility of the population in that country. A key point made in the risk assessment was that this model was developed for oysters, and to use this model for other shellfish species such as clams (which have been recently implicated in septicaemia in the United States of America, Baker-Austin et al. 2020, unpublished data) would need to be adapted accordingly. A key data-gap is where outside of the United States of America these shellfish-associated infections occur regularly.

\subsection{RECENT FAO/WHO ACTIVITIES AND EXPERT MEETINGS ON VIBRIOS}

The FAO/WHO VPRA was released in 2011 and included sections on raw oysters worldwide, blood clams in Thailand and raw fish in Japan. In addition, there were a number of activities based on early drafts and expert consultations. While finalising the Codex Guidelines in the Application of General Principles of Food Hygiene for the Control of pathogenic Vibrio spp. in seafoods, the $41^{\text {st }}$ session of the CCFH recognized the need to provide countries with tools to assist them in the implementation of the guidelines under the various conditions that exist in different regions and countries. Such tools were envisioned to support countries in their efforts to use risk-based approaches in the selection of control measures appropriate for their seafood species, primary production and postharvest practices. Such risk management tools ( $V$. parahaemolyticus calculator and $V$. vulnificus calculator tools) had already been developed for application in the United States of America. However, as it was based on the conditions and data of the United States of America, its broader application could not be recommended without a review of its validity when applied to the non-United States of America scenarios. In light of this, the CCFH requested FAO/WHO convene an Expert Meeting tasked with the

following terms of reference: 
- Conduct validation of the predictive risk models developed by the United States of America based on FAO/WHO risk assessments, with a view toward constructing more applicable models for wide use among member countries, including adjustments for strain virulence variations and ecological factors.

- Review the available information on testing methodology and recommend microbiological methods for Vibrio spp. in order to monitor the levels of pathogenic Vibrio spp. in seafood or seawater, or both.

- Conduct validation of growth rates and doubling times for V.parahaemolyticus and V. vulnificus in Crassostrea virginica (eastern or American oyster) using strains isolated from different parts of the world and different bivalve molluscan species.

The FAO/WHO convened this Expert Meeting on 13-17 September 2010, and a meeting report based on this (MRA20) has been recently published (FAO/WHO, 2020). The outputs from this meeting included the following:

Risk calculators and models: Risk assessment comprises estimation of exposure to the hazard, called "exposure assessment" and characterization of the relationship between the amount or dose of the hazard that is ingested and the probability of illness, or some other measure of harm (FAO/WHO, 2003). Rather than exhaustively validating individual risk models, the working group decided that it would be more appropriate to assess and evaluate existing models to be amended and extended for other uses. In this regard, simplified calculator tools could then be developed to answer separate risk questions routinely, and potentially in different regions and utilising different shellfish species and pathogens. The workshop noted that the V. parahaemolyticus calculator tool may be used to estimate the relative risk reductions, primarily because of the linear dose-response, associated with temperature controls (postharvest refrigeration) in areas in which the strain virulence, initial concentration and growth rates of $V$. parahaemolyticus in the bivalve spp. of concern are similar to the United States of America. The expert group concluded that the V. vulnificus calculator tool is less likely to be applicable to a broader region outside the United States of America due to potential differences in environmental, harvesting and post harvesting parameters, but more significantly due to the nature of the dose-response relationship that is derived completely from the United States of America epidemiological data coupled with estimated exposure levels and is nonlinear. Specific shellfish species might also influence the risk estimate. In addition, the group noted the need to develop a tool that is applicable to particular regions/or and other products, or to answer risk management questions other than postharvest refrigeration, it was preferable to first modify the Joint FAO/WHO Expert Meetings on Microbiological Risk Assessment (JEMRA) risk assessment model used for the 2010 meeting, or develop a new model, that considered and evaluated the influence of other factors including 
salinity, strain differences, temperatures, etc. A simplified calculator tool was then be developed to answer that specific question routinely. Some key data limitations were also noted by the group, notably evidence that the V. parahaemolyticus model currently used overestimated its growth at higher temperatures (for instance > $25{ }^{\circ} \mathrm{C}$ ) in live oysters. This phenomenon requires further investigation. Finally, there was no data to evaluate the performance of the growth models in any other oyster species or other filter feeding shellfish or other seafood and as such its use in these products could not be supported but if used, should be done with clear understanding of the associated uncertainty. Several key recommendations emerged from this meeting:

\section{Suggestions for improvement for the V. parahaemolyticus model:}

- The available V. parahaemolyticus prediction model was is a linear model and therefore may be useful to estimate relative change in risk (percent reduction in risk) for different countries with more virulent strains, only providing that the ranges of doses in that country are much less than the Infectious Dose 50 (ID50) for the more virulent strain (i.e. in the linear range of the dose response relationship).

- There is a need for country-specific assessments (e.g. in Chile) which should be undertaken and which should use an ecological dose-response approach like V. vulnificus DR-assessment (but prospectively); studies should be undertaken in other regions to obtain estimates of dose by sampling at retail.

- There is a need to develop dose-response models that incorporate multiple strains and variations in virulence based on data of relative expression of hemolysins plus differences in prevalence of pathogenic strains in clinical versus environmental isolates.

\section{Suggestions for improvement for the $V$. vulnificus model:}

- Conversely, the use of the V. vulnificus prediction tool outside of the United States of America was not advisable at that time (dose-response nonlinear so not useful as relative risk reduction, different countries might have different prevalence of C-type vs E-type strains in the environment, there may be differences in the proportion of population susceptible, etc.).

- The United States of America V. vulnificus dose-response assessment should be revisited using an approach that incorporates the effect of (a) seasonality of the C vs $\mathrm{E}$ type \& (b) relative virulence of the $\mathrm{C}$ vs $\mathrm{E}$ type e.g. for (a) try logistic regression of type $\mathrm{C}$ vs type $\mathrm{E}$ versus water temperature or season; for (b) 60-fold difference by comparison of prevalence in clinical versus environmental strains.

- The concept of incorporating distributions of susceptibility to infection among the at-risk population should be investigated (e.g. assess the reliability of extrapolation to a country with different prevalence of predisposing conditions). 
Microbiological approaches and techniques: Microbiological monitoring methods, particularly molecular-based approaches, have rapidly evolved recently, particularly since the risk assessment efforts for these pathogens began in the early 2000s. The group noted that because of these rapid changes, it would not be appropriate to make single recommendations regarding choice of molecular targets, detection methodologies, etc. It was recommended, however, that a few options could be considered, which would also address issues such as the type, extent and sampling intensity of a vibrio monitoring programme alongside constraints such as the cost, the speed with which results are required and the technical capacity of testing laboratories. To facilitate data collection, the meeting recommended the establishment of an internationally recognized system for developing criteria and protocols for evaluation of methods and to elaborate performance parameters of methods for detection and enumeration of pathogenic Vibrio spp. in seafood.

FAO/WHO convened an Expert Meeting in 2011 that produced a Guidance document on methods for detection and enumeration of $V$. parahaemolyticus, $V$. vulnificus, including performance characteristics of the methods and the application of these methods for different end uses, ranging from harvest area monitoring, postharvest process verification, end product testing, outbreak investigation and growth studies (FAO/WHO, 2016). Following this, FAO, in collaboration with International Life Science Institute (ILSI) organized two regional training workshops, one in Asia and another in Latin America to disseminate the information on methodology for vibrio studies. 


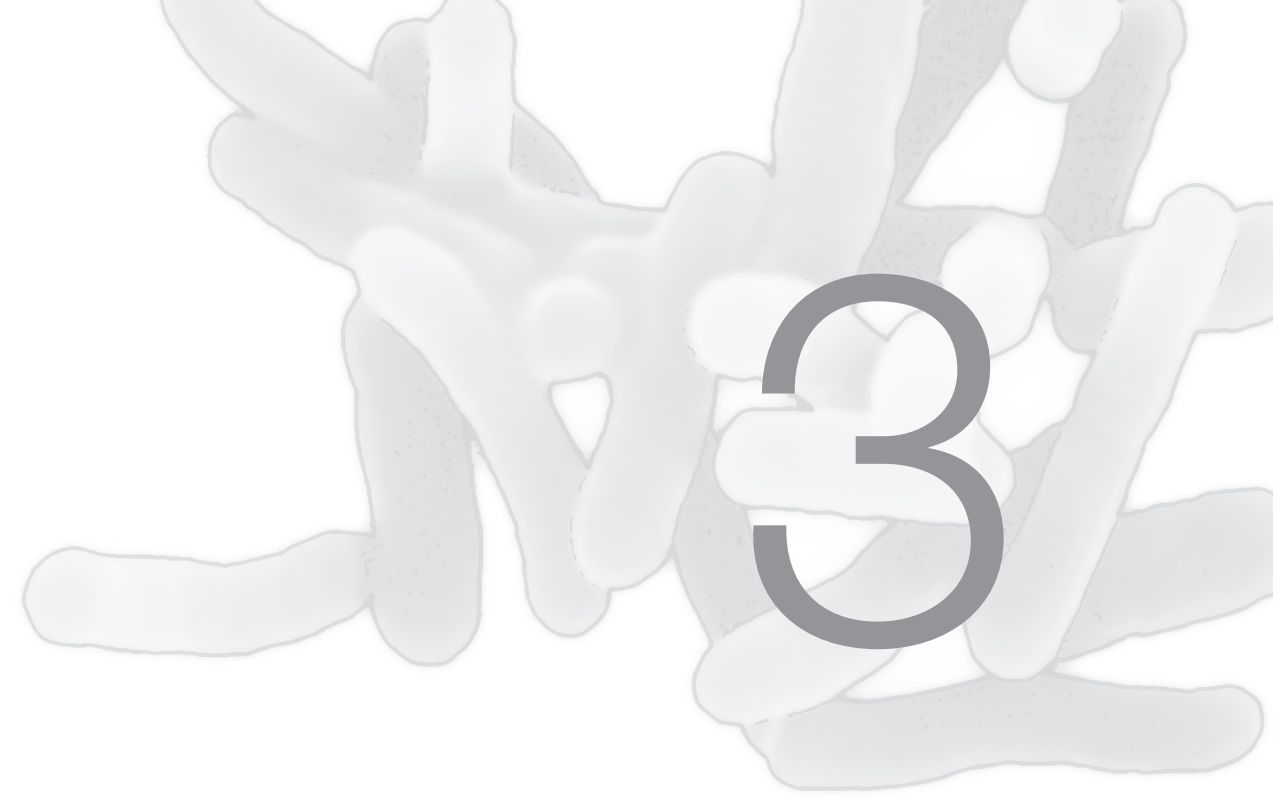

\section{New advances in vibrio science}

\subsection{FAO/WHO MEETING}

The FAO/WHO solicited Cefas to provide an update on key developments that had taken place since the 2010 meeting report. The Joint FAO/WHO Expert Meeting on Microbiological Risk Assessment on V. parahaemolyticus and V. vulnificus took place at Cefas, Weymouth, the United Kingdom, on 13-15 May 2019. The meeting reviewed and updated the existing risk assessment models/tools of $V$. parahaemolyticus and V. vulnificus that could be used to address a range of risk management questions in a number of different regions.

During the workshop, several key areas were identified by the expert working group that had greatly advanced since the 2010 meeting. These are can be summarized into several main areas:

1) Available epidemiology. There are now a variety of epidemiological datasets available (from 2010 onwards) that greatly expand our knowledge regarding the global distribution and clinical impact of $V$.parahaemolyticus and $V$. vulnificus from seafood. The most recent epidemiological data is included in Tables 1 and 2. The emergence of unusual species (e.g. nontoxigenic $V$. cholerae) in seafood-related outbreaks was also noted.

2) Recently available scientific data, in particular information on new pathogenic strains and their geographical spread and clinical incidence, was outlined and discussed.

3) Methods for the detection and characterisation of vibrios of human health relevance. These include new culturing methods as well as novel 
characterisation approaches such as those facilitated by next generation sequencing-based techniques, LAMP, immunocapture approaches, etc.

4) Risk modelling advances. These include approaches for apportioning risk using remote sensing based techniques to measure variables such as temperature and salinity.

5) Advances in best practice. Since the 2010 meeting report, and previous FAO/WHO risk assessment reports published on V. vulnificus (2004) and V. parahaemolyticus (2011), a variety of studies have improved our understanding of practical interventions that can be used to reduce vibriosis risks associated with the consumption of seafood. These include relaying, cooling, post-harvest treatments, etc. These have been summarised here.

6) Climate, demographics and behaviour. There is a much greater understanding of aspects related to human behaviour and also the impact of climate change on risks associated with $V$. vulnificus and $V$. parahaemolyticus. There are also notable changes in demography at a national, regional and global level that may impact human health risk. These have been summarised and discussed further below.

Some vibrio studies have identified that climate, handling practices, resident and emergent vibrio strains and shellfish species may affect the growth of $V$. parahaemolyticus and V. vulnificus - hence more representative data from other regions are required, to determine whether it is appropriate to update these models and tools or if indeed new risk assessments are needed. Since then, there have been many developments in this area over the last decade, and understanding of these organisms and their management continues to evolve. Taking into account those continuous discussions, the meeting reviewed and updated the existing risk assessment models/tools of $V$. parahaemolyticus and $V$. vulnificus that could be used to address a range of risk management questions in a number of different regions.

Experts reviewed the outcomes of the expert meeting in 2010 on the risk assessment tools for $V$. parahaemolyticus and V. vulnificus associated with seafood. Experts agreed that the basic information of pathogenicity (including virulence markers), major factors relevant to the fate of V. parahaemolyticus and V. vulnificus (water temperature and salinity) and other main contents have not been changed; however, there are several models and methods that have become available in the last decade. 


\subsection{RECENTLY AVAILABLE DATA}

Microbiology and microbiological risk assessment are constantly evolving fields, and new developments such as changes in microbiological detection methods, the emergence of new pathogens and pathogenic strains, coupled to a changing environment, among others, provide constant challenges for risk assessors. A variety of scientific developments have taken place in the last decade that have significant ramifications for risk assessment purposes. Some of these highlight scientific facts relevant for consideration within the existing risk assessment model that were not available during earlier meetings or during the previous risk assessment reports in 2005 and 2011. These findings include the following:

Emergence of highly pathogenic strains: New and highly pathogenic strains of $V$. parahaemolyticus have emerged along the eastern seaboard of the United States of America and Europe recently, and since the previous RA work was considered (Martinez-Urtaza et al., 2013). These strains represent an additional concern for risk assessment purposes as they have a significantly lower infectious dose 50 and different growth characteristics compared to "pathogenic" (e.g. $t d h+$ ) V. parahaemolyticus strains used in the 2011 VPRA. Infections associated with these clones have now been reported in Europe and the NE United States of America (Martinez-Urtaza et al., 2013) but also now in Latin America, with cases confirmed in Peru (Abanto et al., 2020). These findings are especially noteworthy, indicating the potential pandemic spread similar to ST3 strains in the 1990's (Nair et al., 2007).

The United States of America risk management tools outlined previously (e.g. in previous MRA documents, MRA 20) did not consider the arrival of new pathogenic strains in a geographical location mediated by human activity or natural events, and how climatic or oceanographic factors, like El Niño and climate change, can influence the dispersal or successful introduction and establishment in natural reservoirs. Although the sources and routes of introduction of these foreign clones remain yet undetermined, a growing body of evidence has linked the epidemic dynamics and spreading of disease in particular regions such as the NE United States of America and Spain to the movement of shellfish species, and in South America to El Niño events. Strikingly, the long-term persistence and presence of environmental isolates indicate the successful establishment of ST36 in environmental reservoirs (Abanto et al., 2020), as evidenced by the overwintering of ST36 in the NE United States of America from 2012-2013; this is especially relevant from a risk assessment perspective. The presence of these strains now in NE United States of America, Latin America, New Zealand and Europe, as well as its traditional host range in the Pacific Northwest, is evidence of successful pandemic spread, and the potential for ongoing risks associated with this particular clonal group. These findings require in-depth 
and judicious consideration from a risk assessment perspective because of the clinical capabilities of these strains as well as the precedent of rapid clonal expansion of these pathogens, such as that seen by the O3:K6 group in the 1990s which caused significant outbreaks globally (Nair et al., 2007).

Ecological variables: The United States of America risk management tool for $V$. parahaemolyticus was based on the presumption that in a geographical area, a certain proportion of $V$. parahaemolyticus strains are pathogenic and that environmental factors like temperature and salinity affect all $V$. parahaemolyticus strains equally. Some recent evidence indicates that certain ecological parameters may favour the proliferation of pathogenic strains over non-pathogenic strains (Baker-Austin et al., 2016). Alongside this, there is emerging data to show that a larger proportion of strains in other regions may be toxigenic (e.g. in the United Kingdom, trh+ are typically up to $50 \%$ of all tested $V$. parahaemolyticus during summer months, Baker-Austin et al. published, FAO/WHO, 2020). Currently, the risk potential of these strains is unknown.

Development of molecular tools: Most of the methods for detection of $V$. parahaemolyticus and V. vulnificus were outlined and described in MRA Series 22 (FAO/WHO, 2016). A multitude of methods for characterization of strains such as improvements in the isolation of these bacteria, serotyping, multi-locus sequence typing, genotyping, and more recently whole genome sequencing have been more widely introduced recently which has improved our understanding and characterization of the risks associated with these bacteria. More recently, the application of molecular approaches, and in particular the use of whole genome analysis, has revolutionized our understanding of these pathogens, but has provided key challenges regarding the importance of strain phylogeny and phylogeography and thus requires more information. Genetic analysis of outbreak strains in the United States of America indicate involvement of both endogenous and nonendogenous emerging strains (Baker-Austin et al., 2018). There is some evidence for global spread of pathogenic strains through oceanic currents, ballast water and movement of shellfish commodities (Martinez-Urtaza et al., 2016; Baker-Austin et al., 2016).

The recent emergence of genomic epidemiology approaches applying nextgeneration sequencing, coupled to open access bioinformatic tools, can now be used to reconstruct the emergence, dispersal, and evolution of these and other important foodborne pathogens. These approaches are typically faster, less expensive and provide greater resolution than traditional subtyping methods such as PCR, multi-locus sequence typing, pulsed field gel electrophoresis and serotyping, which were the approaches of choice available during the most recent (2011) V. parahaemolyticus and $V$. vulnificus risk assessments. The use of sequencing in the 


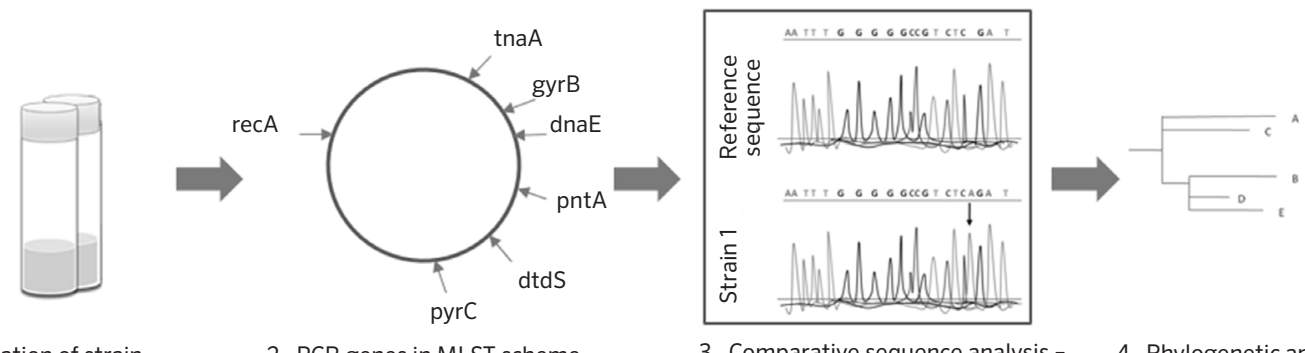

1. Isolation of strain

2. PCR genes in MLST scheme

3. Comparative sequence analysis SNP identfication

4. Phylogenetic analysis

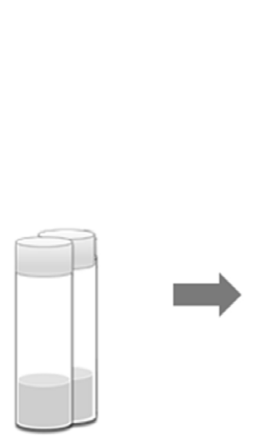

1. Isolation of strain

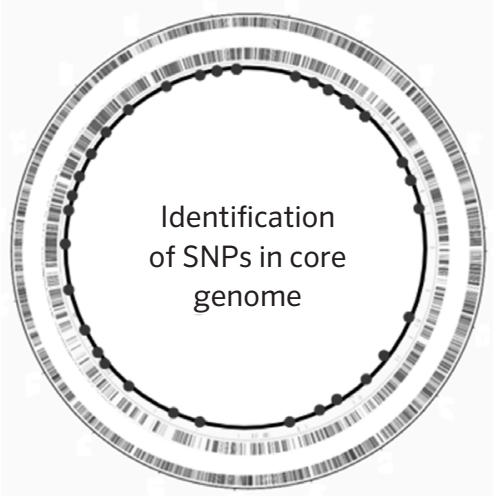

2. NGS of strain - comparative analysis against ref. genome

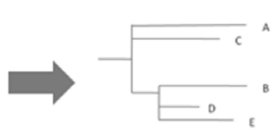

3. Phylogenetic analysis

FIGURE 1. Recent evolution of $V$. parahaemolyticus strain typing approaches. Traditional methods, such as serotyping, pulsed field gel electrophoresis (PFGE), and multi-locus sequence typing (MLST, top) are typically time consuming, expensive and specialist methodologies. MLST using PCR analysis of a small number of core housekeeping genes, coupled to sequencing and identification of mutations (single nucleotide polymorphism, SNPs) were generally capable of distinguishing most strains of clinical interest, such as those implicated in foodborne outbreaks. The advent of whole genome sequence (WGS) based methods has facilitated the identification of several hundred mutations - using the same basic approach at a fraction of the cost and time of traditional methods. These WGS methods have dramatically increased the granularity of analysis, revolutionising the ability to conduct rapid and precise outbreak investigations.

routine analysis of vibrio strains along with the availability of genomic data from vibrio strains collected all around the world have introduced a fundamental change in the way that strains and associated epidemiological metadata are analysed. The possibility of building large datasets of genomes with global coverage has become a routine procedure for the analysis of strains within an epidemiological context, detecting similar strains isolated anywhere in the world and using these strains to infer the colonization history and finally draw the most probable routes 
of dissemination from the original sites of emergence. This new framework for the study of pathogenic populations allows for a precise reconstruction of the migratory routes for the major epidemic clones and this information can be applied to identify potential drivers of dispersal and introduction. The application of new tools has successfully contributed to help reconstruct the colonization history for the major epidemic clones of $V$. parahaemolyticus (Baker-Austin et al., 2018). There are notable limitations to these methods, which can be expensive, technically complex and require carefully-trained staff; however, there are now avenues for support in their use in low and middle-income countries.

Development of satellite risk assessment approaches: In the last decade, a range of risk assessment approaches have been developed utilising satellite measurement. Satellite-based remote sensing for studying marine systems has become a useful tool in predicting human health risks associated with marine bacterial pathogens such as vibrios (Grimes et al., 2014). These globally applicable methods have been used largely to analyse non-cholera Vibrio spp., particularly for bathing water infections and outbreaks associated with seafood consumption (Semenza et al., 2017). This data could be useful to assess (retrospectively) outbreaks and to provide temperature and key environmental data into risk assessment approaches. Some of the risk models developed also have forecasting capabilities, which could be used for risk management purposes. These approaches have been used successfully to analyse environmental conditions such as temperature and salinity, which are well established variables that can modulate vibriosis risk. Numerous studies, such as those focussing on bathing water (Baker-Austin et al., 2016) and shellfishassociated infections (Martinez-Urtaza et al., 2010) have demonstrated the usefulness of these methods to ascribe increased risk prior to and during outbreak episodes. An overview of currently available risk models using these approaches is outlined in Table 3.

Climate change: Because the growth of pathogenic vibrios in the natural environment is largely dictated by temperature, this group of pathogens represent an important and tangible barometer of climate change in marine systems (Baker-Austin et al., 2017). The growth of V. parahaemolyticus and V. vulnificus is proportional to environmental temperatures, and these pathogens grow extremely well above $15^{\circ} \mathrm{C}$. As such, and in a rapidly warming marine environment, there are likely to be a greater number of vibrio-associated human infections. Since the 2004 and 2011 risk assessments a wide variety of studies and a general improvement in analysing the link between vibrios and climate warming have been published that provide a more coherent understanding regarding the role of climate change and risk. A key recent finding is that there has been a significant expansion in coastal regions where these bacteria can proliferate. An overview of how climate change will likely modulate risk was considered in detail during the workshop and is outlined in Section 3.6. 


\subsection{NEWLY AVAILABLE RISK ASSESSMENT MODELS}

Table 3 summarizes the information on all available models. The V. parahaemolyticus risk calculator and $V$. vulnificus risk calculator has been discussed in previous sections. Information about other available models is provided in this section. The models provide outputs ranging from:

1. Abundance of V. parahaemolyticus at harvest and doubling time of V.parahaemolyticus in oysters at certain specified sites in the United States of America (e.g. NOAA model).

2. Occurrence of $V$. vulnificus in water in the Chesapeake Bay (e.g. NOAA model).

3. Environmental suitability for non-cholera Vibrio spp. (e.g. Vibrio Suitability Tool).

TABLE 3. Currently available risk assessment models

\begin{tabular}{|c|c|c|c|c|}
\hline Model & $\begin{array}{l}\text { Parameters used in } \\
\text { the model }\end{array}$ & Output & Availability & $\begin{array}{l}\text { Applicability and } \\
\text { limitations }\end{array}$ \\
\hline $\begin{array}{l}\text { V. parahaemolyticus } \\
(\mathrm{Vp}) \text { risk }\end{array}$ & $\begin{array}{l}\text { Temperature } \\
\text { and Vp levels at } \\
\text { harvest, growth } \\
\text { rate prediction } \\
\text { based on time and } \\
\text { temperature, FAO/ } \\
\text { WHO RA dose } \\
\text { response model }\end{array}$ & $\begin{array}{l}\text { Cases per } \\
100000 \text { serving, } \\
\text { risk reductions } \\
\text { that can be } \\
\text { achieved by } \\
\text { implementing } \\
\text { temperature } \\
\text { control }\end{array}$ & $\begin{array}{l}\text { Excel file } \\
\text { publicly } \\
\text { available (FAO } \\
\text { WHO FS tools) }\end{array}$ & $\begin{array}{l}\text { Regional in the United } \\
\text { States. Assumptions } \\
\text { tested in Connecticut. } \\
\text { Relative risk in regions } \\
\text { may vary. Different } t d h \\
\text { positive strains may have } \\
\text { different attack rates. } \\
\text { The model assumes that } \\
\text { they are all same. } \\
\text { Emergence of new } \\
\text { strains with different } \\
\text { attack rates in a location } \\
\text { is not factored in. } \\
\text { Growth rates may vary in } \\
\text { different bivalve species } \\
\text { and this has not been } \\
\text { factored in this model. }\end{array}$ \\
\hline $\begin{array}{l}\text { V. vulnificus }(\mathrm{Vv}) \\
\text { risk calculator }\end{array}$ & $\begin{array}{l}\text { Temperature } \\
\text { and } \mathrm{V} v \text { levels at } \\
\text { harvest, growth } \\
\text { rate prediction } \\
\text { based on time and } \\
\text { temperature, FAO/ } \\
\text { WHO RA dose } \\
\text { response model }\end{array}$ & $\begin{array}{l}\text { Cases per } \\
100000 \text { serving, } \\
\text { risk reductions } \\
\text { that can be } \\
\text { achieved by } \\
\text { implementing } \\
\text { temperature } \\
\text { control }\end{array}$ & $\begin{array}{l}\text { Excel file } \\
\text { publicly } \\
\text { available FAO } \\
\text { WHO FS tools }\end{array}$ & $\begin{array}{l}\text { Dose response based } \\
\text { only on the United States } \\
\text { epidemiological data, } \\
\text { hence only applicable in } \\
\text { the United States }\end{array}$ \\
\hline $\begin{array}{l}\text { Vibrio Suitability } \\
\text { Tool }\end{array}$ & $\begin{array}{l}\text { Salinity, sea surface } \\
\text { temperature }\end{array}$ & $\begin{array}{l}\text { Predicts risk of } \\
\text { non-cholera vibrio } \\
\text { infections based } \\
\text { on exposure using } \\
\text { model described } \\
\text { by Baker Austin et } \\
\text { al., } 2013 \text {. }\end{array}$ & $\begin{array}{l}\text { ECDC E3 } \\
\text { Geoportal }{ }^{1} \text { and } \\
\text { NOAA Atlantic } \\
\text { OceanWatch } \\
\text { ERDDAP } \\
\text { Server }^{2}\end{array}$ & $\begin{array}{l}\text { Management tool to } \\
\text { facilitate harvest and use } \\
\text { of recreational water low } \\
\text { risk period. Validated for } \\
\text { Baltic Sea, possibly, has } \\
\text { global application. The } \\
\text { output does not provide } \\
\text { information on the type } \\
\text { of Vibrio spp. that may } \\
\text { be involved. Considers } \\
\text { only water exposure, } \\
\text { though it is assumed } \\
\text { that wound exposure and } \\
\text { food exposure may result } \\
\text { in similar infection rates. }\end{array}$ \\
\hline
\end{tabular}

(cont.) 


\begin{tabular}{|c|c|c|c|c|}
\hline Model & $\begin{array}{l}\text { Parameters used in } \\
\text { the model }\end{array}$ & Output & Availability & $\begin{array}{l}\text { Applicability and } \\
\text { limitations }\end{array}$ \\
\hline $\begin{array}{l}\text { NOAA National } \\
\text { Center for Coastal } \\
\text { Ocean Science } \\
\text { (NCCOS) vibrio } \\
\text { predictive model }\end{array}$ & $\begin{array}{l}\text { Temperature, } \\
\text { salinity and } \\
\text { growth rate of } V . \\
\text { parahaemolyticus } \\
\text { and occurrence } \\
\text { of } V \text {. vulnificus in } \\
\text { Chesapeake Bay. }\end{array}$ & $\begin{array}{l}\text { Expected } V . \\
\text { parahaemolyticus } \\
\text { levels at harvest } \\
\text { and after } \\
\text { postharvest } \\
\text { handling in } \\
\text { Chesapeake } \\
\text { Bay, doubling } \\
\text { time for V. } \\
\text { parahaemolyticis } \\
\text { in specified } \\
\text { regions, V. } \\
\text { vulnificus } \\
\text { occurrence in } \\
\text { Chesapeake Bay. }\end{array}$ & Web based ${ }^{3}$ & $\begin{array}{l}\text { The model predicts } \\
V . \text { parahaemolyticus } \\
\text { levels in certain specific } \\
\text { geographical regions } \\
\text { in the United States } \\
\text { (e.g. Chesapeake } \\
\text { Bay, Delaware, Pacific } \\
\text { Northwest etc) and } \\
\text { occurrence of } V \text {. } \\
\text { vulnificus in Chesapeake } \\
\text { Bay. Provides shellfish } \\
\text { related guidance in } \\
\text { specified regions. } \\
\text { Needs to be adapted to } \\
\text { other regions. Can do } \\
\text { region specific scenario } \\
\text { analysis. The limitation } \\
\text { is that relation between } \\
\text { risk and abundance may } \\
\text { vary in different regions } \\
\text { based on strains, attack } \\
\text { rates etc. }\end{array}$ \\
\hline $\begin{array}{l}\text { V. vulnificus forecast } \\
\text { model }\end{array}$ & $\begin{array}{l}\text { Salinity and } \\
\text { temperature }\end{array}$ & $\begin{array}{l}\text { Presence and } \\
\text { density of } V \text {. } \\
\text { vulnificus }\end{array}$ & $\begin{array}{l}\text { Published } \\
\text { (Oliver and } \\
\text { Kaper, 2001, } \\
\text { 2007) }\end{array}$ & $\begin{array}{l}\text { Relation between risk } \\
\text { and abundance may } \\
\text { vary in different regions. } \\
\text { Does not factor in } \\
\text { abundance of clinical and } \\
\text { environmental strains. }\end{array}$ \\
\hline
\end{tabular}

\footnotetext{
https://e3geoportal.ecdc.europa.eu/SitePages/Vibrio\%20Map\%20Viewer.aspx

https://cwcgom.aoml.noaa.gov/erddap/search/index.html?searchFor=vibrio

https://coastalscience.noa.gov/products/vibriopredictive-models/
}

NOAA model: The model available on the website of National Center for Coastal Ocean Science (NCCOS) predicts abundance of V. parahaemolyticus in certain specified locations in the United States of America based on temperature, salinity and USFDA model for growth of this organism. The output is presented differently for different locations. For example, $V$. parahaemolyticus levels in oysters at harvest from Gulf of Mexico and Tampa Bay. For Delaware Bay, Pacific Northwest, and Northeast $V$. parahaemolyticus doubling time is predicted hourly for first 36 hours, every 3 hours till 72 hrs and every 6 hrs for 7 days. This could be used by shellfish farmers to plan harvesting and cooling strategies. For Chesapeake Bay, $V$. parahaemolyticus levels at harvest and postharvest (for $10 \mathrm{hrs}$ based on regionally adjusted $1 \mathrm{KM}$ air temperature) is predicted.

For V. vulnificus, only occurrence in water in Chesapeake Bay has been presented and no shellfish guidance is indicated. This information may be used by those likely to be exposed to water in Chesapeake Bay. Vibrio vulnificus levels in water may also be used by shellfish harvesters since levels in water and oysters would be 
related. One of the limitations of the model is that risk of infection is not predicted. These models cannot be directly used by other countries, but they may develop their own model based on local data on temperature, salinity and growth of $V$. parahaemolyticus in their own shellfish species.

\section{Vibrio Suitability Tool}

Link: https://e3geoportal.ecdc.europa.eu/SitePages/Vibrio\%20Map\%20Viewer. aspx (Baltic Sea) and https://cwcgom.aoml.noaa.gov/erddap/search/index. html?searchFor=vibrio (Global Fields)

The Vibrio Suitability Tool is intended to inform public health professionals about environmental suitability for non-cholera vibrio to be used as a tool for adoption of prevention measures and public awareness. The model is based on the methodology described in Baker-Austin et al. (Baker-Austin et al., 2013) and uses salinity and sea surface temperature (SST) to estimate the environmental suitability for vibrios in coastal waters in relation to disease risk. The model is based on data of non-cholera vibrio infections (vibriosis) from previous studies relating number of infections and environmental variables. The algorithm is a general model with thresholds for salinity and SST, 28 Practical Salinity Units (PSU) and $18^{\circ} \mathrm{C}$ respectively, that allows the inclusion of areas suitable for the occurrence of all human pathogenic Vibrio spp. The output of the model delineates coastal areas with environmental conditions suitable for the occurrence of human pathogenic Vibrio spp. that can drive the emergence of infections. The areas of environmental suitability are colour coded, ranging from zero to a maximum which is determined by the highest sea surface temperature value. The model has been developed for the Baltic Sea and is under evaluation with epidemiological data from other parts of the world. However, preliminary analyses of the outputs based on a review of Vibrio spp. and epidemiological data and literature review have shown similar results for other regions (Semenza et al., 2017). Environmental parameters used in the model are exclusively salinity and sea surface temperature and no other critical abiotic and biotic factors governing the occurrence of Vibrio spp. in the marine environment is considered. As the last layer of complexity, there is a large amount of demographic, behavioural and epidemiological information shaping the risk of exposure. These factors can of course leverage the overall exposure of the population.

\subsection{RECOMMENDATIONS FOR BEST PRACTICE}

The efficacy of various postharvest treatment technologies, alone or in combination, have been previously described (see MRA20). Below is a summary of some new approaches and data regarding postharvest treatment technologies that have emerged in the last decade and that were discussed at the most recent expert workshop. 
Harvesting curfews: Harvesting curfews aim to ensure oysters are harvested under conditions which coincides with the periods of lowest contamination and growth of $V$. parahaemolyticus in oysters. Examples include early morning harvests (before the maximum heat of the day) and within specific tidal periods. The latter example is based on the scientific observation that $V$. parahaemolyticus levels increase when oysters are exposed on the sunny mudflats by a receding tide, then decrease when the tidal waters submerge the shellfish and filter-feeding recommences (Jones et al., 2016). However, it must be recognized that the climatic and tidal conditions in other countries are different around the world. Much of the United States of America tidal $V$. parahaemolyticus research relates to situations where oysters are grown directly on the substrate; the substrates materials vary; diurnal temperatures are often higher than other countries daily maximum; and there are spatial and temporal differences in the tidal cycles. Local research should be undertaken to ascertain the harvesting and environmental conditions conducive to mitigating the vibriosis food safety risk.

Harvesting cessation: Harvesting cessation can be used both as a reactive response to reported illnesses and a proactive measure to prevent illness. Proactive measures can be based on temperature or salinity levels in the environment, measured or based on remote sensing models (reference to NOAA and EU models), or can be based on restrictions for harvesting during months traditionally associated with peak illness. The NSSP has also developed reactive controls including time to refrigeration and closures based on reported cases over selected periods.

Resubmersion: Re-submerging is used in Canada and the United States of America as a V. parahaemolyticus mitigation process and the USFDA has validated this process. The resubmerging practice is usually defined as harvesting, culling and placing oysters in larger cages for re-submerging in a deeper water body or for re-submersion by the tide. Consideration of these practices alongside other control measures (such as for biotoxin and classification status) should be also taken into account. USFDA studies found that oysters grown on both the east and west coast, containing elevated $V$. parahaemolyticus caused by pre-submerging conditions, returned to background levels after one tidal cycle following re-immersion (ISSC, 2017). This practice requires availability of water space deep enough for re-submerging the harvested oysters. Industry would need to design systems whereby the intertidal product is harvested, shifted and anchored in deeper water or submerged in the incoming tidal waters on the lease, in a manner from which they can be directly harvested. For example, a single commercial shellfish operator uses a barge fitted with a crane could harvest the cages of re-submerged oysters.

Deep water suspension: Deep water suspension, or the movement of oyster nets into cooler waters when water temperatures exceed $15^{\circ} \mathrm{C}$ should be considered as 
method of vibriosis risk reduction (McLaughlin et al., 2005). To date, little data on this intervention exists, however it may represent a cost-effective management option. As with other control measures, consideration of how these practices may impact other factors (e.g. for biotoxin and classification status) should also be taken into account.

Relaying: There is limited information on the success of relaying as a treatment step to remove $V$. parahaemolyticus. However, recent USFDA studies confirm that relaying to higher salinity and/or cooler waters shows promise for reducing $V$. parahaemolyticus levels, with around seven days sufficient time to reduce $V$. parahaemolyticus levels in oysters (ISSC, 2017). It should be recognized that there is the potential for $V$. parahaemolyticus in the relayed lots to contaminate other shellstock growing in the new water space.

Depuration: Depuration or purification is one of the major treatment processes in controlling the public health risks associated with microbially-contaminated shellfish. Depuration is the process by which shellfish naturally relinquish any microbiological component bioaccumulated in the environment. According to the Codex Code of Recommended Practice for Fish and Fishery Products, depuration means the reduction of microorganisms to a level acceptable for direct consumption by the process of holding live bivalve molluscs for a period of time under approved, controlled conditions in natural or artificial sea water suitable for the process, which may be treated or untreated. Historically shellfish depuration has not been considered an appropriate process for mitigating or eliminating the vibriosis food safety risk. Unfortunately, depuration has been shown to be ineffective in reducing a range of pathogenic Vibrio spp., such as $V$. cholerae and $V$. parahaemolyticus from bivalve matrices (Croci et al., 2002). However, a recent study (Shen et al., 2019) demonstrated that optimal $V$. parahaemolyticus depuration occurred at a temperature of $12.5^{\circ} \mathrm{C}$ and stocking density of two oysters/ $\mathrm{L}$ of artificial seawater. The mean depuration time to achieve a target reduction of $3.52 \log _{10}$ (NSSP reduction target) was 3.17 days, and five days to achieve a level of $<30 \mathrm{MPN} / \mathrm{g}$.

Temperature Controls: Experiments with oysters artificially contaminated with $V$. parahaemolyticus found that treatment of $50^{\circ} \mathrm{C}$ for 10 minutes was needed to reduce the concentration by $>5 \log _{10} \mathrm{MPN} / \mathrm{g}$ (Ye et al., 2012). Treatment at $50^{\circ} \mathrm{C}$ for only 5 minutes or treatment at $45^{\circ} \mathrm{C}$ for 20 minutes only achieved reductions of 3.9 and $2.6 \log _{10} \mathrm{MPN} / \mathrm{g}$, respectively. An earlier study (Andrews et al., 2000) had measured a $5 \log$ reduction of $V$. parahaemolyticus in oysters after 5 minutes at $50^{\circ} \mathrm{C}$. The difference may be due to different strains or methods (e.g. Andrews et al. used a kettle at $55^{\circ} \mathrm{C}$ to initially heat the oysters to $50^{\circ} \mathrm{C}$, while Ye et al. (2012) used a water bath at $50^{\circ} \mathrm{C}$ (Ye et al., 2012). Ice slurries were effective for rapidly cooling oysters $\left(24^{\circ} \mathrm{C}\right.$ to $10^{\circ} \mathrm{C}$ within 12 minutes), but repeated dipping of oysters caused 
the ice to become contaminated with faecal coliforms, Clostridium perfringens, V. vulnificus and total V. parahaemolyticus (Lydon et al., 2015). However, the concentrations of Vibrio spp. were unchanged in the flesh of the oysters after 15 minutes submersion in the contaminated ice slurry. Another study found that onboard and dockside icing did not predictably reduce the concentration of $V$. parahaemolyticus in oysters, and icing significantly and negatively affected oyster survival (Melody et al., 2008). The impact of climate change on shellfish safety may mean it is necessary for countries and regions undergoing increased risk to assess and potentially implement enhanced control measures, such as cold-chain interventions recently adopted in the United States of America to reduce illnesses associated with $V$. parahaemolyticus.

Cryogenic individual quick freezing (IQF) with extended storage: IQF is an USFDA-approved control for Vibrio spp. IQF involves the use of cryogenic or blast freezing technology to rapidly lower the product temperature below freezing. This process results in a reduction in the number of temperature sensitive pathogens. Some pathogens are more sensitive to freezing than are others. For example, $V$. parahaemolyticus and $V$. vulnificus are especially sensitive to colder temperatures. To reduce V.parahaemolyticus and/ or V. vulnificus to nondetectable levels, the IQF process is followed by a period of frozen storage, which may vary depending on organism (USFDA, 2011).

High hydrostatic pressure: High pressure processing (HPP) is the application of hydrostatic compression in the range of 14500 to 145000 pound per square inch (100 to 1000 megapascal (MPa)) which inactivates $V$. parahaemolyticus and $V$. vulnificus by damaging the cell membrane, cell wall and degrading cellular proteins (Berlin et al., 1999; Wang et al., 2013). These pressures are capable of inactivating pressure-sensitive pathogens, especially vegetative forms. The effectiveness of the process is dependent upon the amount of pressure applied, the process temperature, and the duration of the process. However other organoleptic changes, such as texture, viscous liquor and a "plumper" appearance have been reported in shellfish. Additionally, the pressure facilitates oyster adductor muscle changes; hence, HPP may result in a shucked oyster (USFDA, 2011). HPP is being increasingly being used for minimising the risk of pathogens in seafood. Vibrio spp. have been reported to be sensitive to high hydrostatic pressure. This approach was previously outlined in MRA20 (FAO/WHO, 2020). In a recent meta-review of post-harvest practices and processes (PHP) approaches to reduce risks associated with Vibrio parahaemolyticus, high hydrostatic pressure consistently emerged as the most effective PHP approach in reducing abundance of $V$. parahaemolyticus (Spaur et al., 2020). 
Low dose gamma radiation: Vibrio spp. are among the most radiation-sensitive bacteria. Irradiation involves exposing oysters to ionising energy, either gamma rays, machine-generated electrons or X-rays. An ionising irradiation dose of 1.0 kGy reduced $V$. vulnificus artificially bioaccumulated in whole shell oysters from $107 \mathrm{MPN} / \mathrm{g}$ to nondetectable levels and had the same effect on naturally present V. vulnificus (103 MPN/g) (Andrews et al., 2003; Ama, Hamdy and Toledo, 1994).

Mild heat treatment: New data on the effect of mild heat treatment on $V$. parahaemolyticus and $V$. vulnificus concentration in shellfish have been published since $2003 \mathrm{FAO} / \mathrm{WHO}$ risk assessment and some results are promising, but still it would be preferable to perform validation at specific conditions/practices before implementation of the PHP and its inclusion in the model.

Freezing: V. parahaemolyticus present in shucked and shell stock oysters does not tolerate freezing well. Detrimental effects of freezing were greater at $-18^{\circ} \mathrm{C}$ than at $-30^{\circ} \mathrm{C}$, consistent with greater bacterial damage at the higher temperatures due to the formation of larger intracellular ice crystal formation (Shen et al. 2009).

\subsection{MICROBIOLOGICAL TESTING METHODS}

A variety of approaches have been developed for the isolation, detection, enumeration and characterisation of vibrios from environmental matrices such as water (American association for wastewater 1997) and shellfish (Hartnell et al., 2018). Since the 2005 and 2011 risk assessment exercises were completed a range of advances in testing methods have been published. In particular, an international standard method for the detection of $V$. parahaemolyticus and $V$. vulnificus in seafood products has been established and published (ISO 21872-1), which includes options for conventional and real-time PCR detection of these pathogens (Hartnell et al., 2018; ISO, 2017). There has also been a significant amount of work carried out in the arena of method standardization in the last decade, for instance with underlying performance data to underpin choice of molecular targets, such as for PCR and qPCR for pathogenic vibrios. Previous guidance was developed in response to a request to FAO/WHO from the 42nd Session of the Codex Committee on Food Hygiene to provide recommendations on a range of test methods for quantifying $V$. parahaemolyticus (total and pathogenic) and $V$. vulnificus in seawater and bivalves, and to facilitate performance evaluation of the methods (FAO/WHO, 2016). A number of key recommendations were subsequently outlined through this work and during the recent expert meeting: 
- Establish an internationally recognized system for developing criteria and protocols for evaluation of method performance parameters of molecular detection methods for pathogenic Vibrio spp. in seafood (explore similar approach for other pathogen/commodity pairs).

- Examine appropriateness of coupling methods performance and analyst proficiency evaluation.

- Develop a collection of appropriate reference material including bacterial strains and sample matrix.

- Explore the development of a PCR network patterned after Global FoodNet.

- Refer to MRA22 (2016): Selection and application of methods for the detection and enumeration of human-pathogenic halophilic Vibrio spp. in seafood.

- Determine the importance and applicability of traditional virulence factors (e.g. $t$ dh/trh in V. parahaemolyticus) as targets for both the detection and enumeration across clinical, environmental and food matrices.

Several key datagaps were also identified. These include approaches to infer further characterization of strains (e.g. serotyping, MLST, genotyping, ATBR, WGS); virulence testing; gene expression levels; strain phylogeny and phylogeography. A selection of the most important methods pertaining to vibrios - in particular for the isolations, enumeration and characterisation of these bacteria from a variety of clinical, environmental and foodbased matrices was compiled by the expert group (Table 4):

TABLE 4. Commonly used microbiological and molecular methods applied in the isolation and characterisation of Vibrio parhaemolyticus and Vibrio vulnificus.

\begin{tabular}{|c|c|c|c|}
\hline $\begin{array}{l}\text { Diagnostic } \\
\text { Method }\end{array}$ & Relevant applications & Limitations & $\begin{array}{l}\text { Relevant } \\
\text { reference }\end{array}$ \\
\hline $\begin{array}{l}\text { Vibrio enrichment } \\
\text { on solid media }\end{array}$ & $\begin{array}{l}\text { Thiosulfatecitratebile salts (TCBS) } \\
\text { agar is a standard medium used } \\
\text { commonly for the selective } \\
\text { isolation and further subculturing } \\
\text { and purification of vibrios. Strains } \\
\text { which are able to use sucrose will } \\
\text { form yellow colonies on TCBS such } \\
\text { as } V \text {. cholerae and V. alginolyticus, } \\
\text { while the other pathogenic species } \\
\text { such as V. parahaemolyticus, } \\
\text { and } V \text {. vulnificus produce green } \\
\text { colonies. Other media types such as } \\
\text { blood agar and chromagar are used } \\
\text { to isolate } V . \text { parahaemolyticus } \\
\text { and CPC (cellobiose-polymyxin } \\
\text { B-colistin agar) is frequently used } \\
\text { for isolation of } V \text {. vulnificus. }\end{array}$ & $\begin{array}{l}\text { Certain Vibrio spp. such as } V \text {. } \\
\text { vulnificus can struggle to grow } \\
\text { on TCBS media. } \\
\text { Food, especially seafood, } \\
\text { may contain large numbers } \\
\text { of bacteria, including } \\
\text { nonpathogenic Vibrio spp. } \\
\text { which may grow through the } \\
\text { selective culture process. } \\
\text { Subculture of small numbers } \\
\text { of colonies may result in } \\
\text { potentially pathogenic species } \\
\text { being missed. }\end{array}$ & $\begin{array}{l}\text { Hartnell et al. } \\
\text { (2018). }\end{array}$ \\
\hline
\end{tabular}




\begin{tabular}{|c|c|c|c|}
\hline $\begin{array}{l}\text { Diagnostic } \\
\text { Method }\end{array}$ & Relevant applications & Limitations & $\begin{array}{l}\text { Relevant } \\
\text { reference }\end{array}$ \\
\hline Toxin testing & $\begin{array}{l}\text { Commercial kits are available } \\
\text { to test for the thermostable } \\
\text { direct hemolysin (TDH) of } V \text {. } \\
\text { parahaemolyticus. Screening } \\
\text { colonies of V. parahaemolyticus on } \\
\text { Wagatsuma agar to detect strains } \\
\text { that are TDH-positive are termed } \\
\text { "Kanagawa positive" via the } \\
\text { identification of hemolysis around } \\
t d h+\text { colonies. }\end{array}$ & $\begin{array}{l}\text { Will not identify non-tdh Vibrio } \\
\text { parahaemolyticus strains, } \\
\text { so limited applicability for } \\
\text { routine testing of clinical and } \\
\text { environmental strains. }\end{array}$ & $\begin{array}{l}\text { Wagatsuma S. } \\
\text { (1968). }\end{array}$ \\
\hline Serotyping & $\begin{array}{l}\text { Usually, the in-depth } \\
\text { identification and subtyping } \\
\text { of } V \text {. parahaemolyticus is } \\
\text { performed by serological tests. } \\
V \text {. parahaemolyticus is classified } \\
\text { by serotyping and the serotypes } \\
\text { of } V \text {. parahaemolyticus are } \\
\text { determined by the combination of } \\
\text { somatic (O) antigens and capsular } \\
\text { (K) antigens. Testing typically } \\
\text { involves serological analysis } \\
\text { of all strains determined by } \\
\text { agglutination using commercially } \\
\text { available } V \text {. parahaemolyticus } \\
\text { antisera. Clinically relevant } V . \\
\text { parahaemolyticus infections } \\
\text { are usually associated with } \\
\text { pathogenic strains of several } \\
\text { important serotypes (clinical } \\
\text { e.g. O3:K6, O4:K12 etc); whereas } \\
\text { nonpathogenic strains comprise a } \\
\text { broader array of serotypes. }\end{array}$ & $\begin{array}{l}\text { Agglutination using } \\
\text { commercially available testing } \\
\text { approaches can be subjective, } \\
\text { and require experience and } \\
\text { training in interpretation. Kits } \\
\text { are often expensive, with a } \\
\text { limited shelf life. No scheme } \\
\text { for } V \text {. vulnificus. }\end{array}$ & $\begin{array}{l}\text { Sakazaki et al. } \\
\text { (1968). }\end{array}$ \\
\hline $\begin{array}{l}\text { Immunomagnetic } \\
\text { Separation after } \\
\text { Enrichment }\end{array}$ & $\begin{array}{l}\text { Immunomagnetic separation is } \\
\text { generally used to improve the } \\
\text { yield of a particular strain after } \\
\text { enrichment. The process is based } \\
\text { on the use of a specific antiserum } \\
\text { for the strain being sought (for } \\
\text { example } V \text {. parahaemolyticus } \\
\text { O3:K6) which is added to uncoated } \\
\text { immunomagnetic beads. } \\
\text { Immunomagnetic separation (IMS) } \\
\text { generally consists of two steps: the } \\
\text { incubation of immunomagnetic } \\
\text { beads (IMBs) with an enriched } \\
\text { bacterial culture followed by a } \\
\text { washing step to remove nontarget } \\
\text { bacteria in a given sample. }\end{array}$ & $\begin{array}{l}\text { Some issues with nonspecific } \\
\text { reactivity of antigens. For } \\
\text { broad testing applications } \\
\text { requires the generation of } \\
\text { many antigens which can be } \\
\text { expensive to produce. }\end{array}$ & $\begin{array}{l}\text { Tomoyasu et al. } \\
\text { (1992). }\end{array}$ \\
\hline
\end{tabular}




\begin{tabular}{|c|c|c|c|}
\hline $\begin{array}{l}\text { Diagnostic } \\
\text { Method }\end{array}$ & Relevant applications & Limitations & $\begin{array}{l}\text { Relevant } \\
\text { reference }\end{array}$ \\
\hline $\begin{array}{l}\text { Biochemical } \\
\text { identification }\end{array}$ & $\begin{array}{l}\text { Most biochemical tests use a } \\
\text { variety of specific miniaturized } \\
\text { growth substrates to identify } \\
\text { bacterial strains. Typically, } \\
\text { dehydrated media with specific } \\
\text { chemically-defined compositions } \\
\text { are used for each test. Growth } \\
\text { of bacteria is used to detect } \\
\text { enzymatic activity, mostly related } \\
\text { to fermentation of carbohydrate } \\
\text { or catabolism of proteins or amino } \\
\text { acids. Generally quick and simple } \\
\text { to use, and inexpensive. }\end{array}$ & $\begin{array}{l}\text { Clinical isolates of } \\
\text { certain species such as } V \text {. } \\
\text { parahaemolyticus can show } \\
\text { significant differences in } \\
\text { up to five biochemical tests } \\
\text { used. Certain standardized } \\
\text { biochemical tests can struggle } \\
\text { to differentiate vibrio species. } \\
\text { Some testing approaches may } \\
\text { be subjective and open to } \\
\text { operator bias. }\end{array}$ & $\begin{array}{l}\text { Martinez-Urtaza } \\
\text { et al. (2006). }\end{array}$ \\
\hline PCR testing & $\begin{array}{l}\text { Widely used method for the } \\
\text { detection of isolated bacteria } \\
\text { utilizing specific primer sets that } \\
\text { are amplified using repeated PCR } \\
\text { cycling. Primer sets for all major } \\
\text { Vibrio species and pathotypes now } \\
\text { well established. More in-depth } \\
\text { molecular characterization, such } \\
\text { as PCR of the virulence genes for } \\
\text { vibrio pathogens, e.g. tdh/trh } \\
\text { analysis of V. parahaemolyticus, } \\
\text { as well as a variety of virulence- } \\
\text { associated PCR tests for V. } \\
\text { vulnificus can be carried out } \\
\text { for further analyses. Extremely } \\
\text { sensitive, rapid, easy to use and } \\
\text { inexpensive. Well standardized and } \\
\text { protocols freely available. }\end{array}$ & $\begin{array}{l}\text { PCR requires that sequence } \\
\text { information is available for } \\
\text { at least a part of the DNA } \\
\text { that is to be amplified, and } \\
\text { as such requires sequencing } \\
\text { data which may limit uses } \\
\text { for new or emerging strains. } \\
\text { Because of the sensitivity } \\
\text { of PCR, contamination and } \\
\text { false-positives can be an issue. } \\
\text { Does not provide quantitative } \\
\text { information. }\end{array}$ & $\begin{array}{l}\text { Bej et al. (1999). } \\
\text { andHill et al. } \\
\text { (1991). }\end{array}$ \\
\hline Realtime PCR & $\begin{array}{l}\text { Real-time PCR utilizes probes that } \\
\text { are labeled with two fluorescent } \\
\text { dyes that emit at different } \\
\text { wavelengths during hydrolysis } \\
\text { catalyzed during the PCR cycle. The } \\
\text { emission is subsequently detected } \\
\text { during PCR cycling using optical } \\
\text { sensors. The probe sequence is } \\
\text { intended to hybridize specifically } \\
\text { to the DNA target region of } \\
\text { interest, which is located between } \\
\text { the two PCR primers. A rapid, } \\
\text { specific and quantitative method, } \\
\text { real-time PCR is also inexpensive } \\
\text { and allows highthroughput testing } \\
\text { of strains derived from clinical, } \\
\text { environmental and food sources. } \\
\text { Primer and probe sets for all major } \\
\text { Vibrio species and pathotypes now } \\
\text { well established. }\end{array}$ & $\begin{array}{l}\text { Although real-time PCR is } \\
\text { quantitative, multiplexing } \\
\text { reactions can be difficult } \\
\text { to optimize. As with } \\
\text { conventional PCR, because } \\
\text { real-time PCR is extremely } \\
\text { sensitive, contamination and } \\
\text { falsepositives can be an issue. } \\
\text { Requires the use of a real-time } \\
\text { PCR machine which can be } \\
\text { costly. Probes for certain } \\
\text { multiplex reactions can also be } \\
\text { expensive. }\end{array}$ & $\begin{array}{l}\text { Nordstrom. } \\
\text { (2007). and } \\
\text { Campbell \& } \\
\text { Wright. (2003). }\end{array}$ \\
\hline
\end{tabular}




\begin{tabular}{|c|c|c|c|}
\hline $\begin{array}{l}\text { Diagnostic } \\
\text { Method }\end{array}$ & Relevant applications & Limitations & $\begin{array}{l}\text { Relevant } \\
\text { reference }\end{array}$ \\
\hline $\begin{array}{l}\text { Multi-locus } \\
\text { sequence typing } \\
\text { (MLST) }\end{array}$ & $\begin{array}{l}\text { MLST is a technique used for } \\
\text { the subtyping of multiple loci, } \\
\text { typically derived via PCR or from } \\
\text { whole genome sequencing-based } \\
\text { analyses. Typically, the procedure } \\
\text { subtypes isolates using the DNA } \\
\text { sequences of a small number } \\
\text { (5-8) of highly conserved genes, } \\
\text { such as housekeeping genes. } \\
\text { Schemes have been developed } \\
\text { for } V \text {. parahaemolyticus. Methods } \\
\text { are rapid and robust and are } \\
\text { amendable for larger and more } \\
\text { comprehensive analyses using } \\
\text { WGS-derived datasets. }\end{array}$ & $\begin{array}{l}\text { Limited scheme for } V \text {. } \\
\text { vulnificus. Approach being } \\
\text { refined and superseded by } \\
\text { WGS-enabled approaches. } \\
\text { Databases required regular } \\
\text { updating and maintenance. }\end{array}$ & $\begin{array}{l}\text { González- } \\
\text { Escalona et al. } \\
\text { (2008). and } \\
\text { Bisharat et al. } \\
\text { Hybrid Vibrio } \\
\text { vulnificus. } \\
\text { (2005). } 040440\end{array}$ \\
\hline $\begin{array}{l}\text { Whole genome } \\
\text { sequencing-based } \\
\text { methods }\end{array}$ & $\begin{array}{l}\text { Whole genome sequencing } \\
\text { is the process of determining } \\
\text { the complete DNA sequence } \\
\text { of a specific genome. Typically, } \\
\text { bacterial isolates are DNA } \\
\text { extracted, and the DNA is sheared } \\
\text { into smaller fragments where } \\
\text { it can be sequenced using a } \\
\text { variety of chemical methods. } \\
\text { Following sequencing, the DNA is } \\
\text { assembled, and strains of interest } \\
\text { can be analyzed using a variety } \\
\text { of bioinformatic approaches to } \\
\text { infer phylogenetic relationships, } \\
\text { evolutionary history as well as } \\
\text { the presence of virulence and } \\
\text { antibiotic resistance genes. Whole } \\
\text { genome sequencing methods } \\
\text { offer unparalleled resolution and } \\
\text { information regarding the genome } \\
\text { of analyzed isolates. The process } \\
\text { is rapid and now extremely cost } \\
\text { effective. }\end{array}$ & $\begin{array}{l}\text { Start up costs of purchasing } \\
\text { a next generation sequencer } \\
\text { can be expensive. Requires } \\
\text { dedicated staff trained in the } \\
\text { use of methods. Required } \\
\text { assistance with interpretation } \\
\text { for in-depth bioinformatic } \\
\text { analysis, as well as computing } \\
\text { support for analyses. }\end{array}$ & $\begin{array}{l}\text { Chen et al. } \\
\text { (2003). } \\
\text { Makino et al. } \\
\text { (2003). } \\
\text { Gonzalez- } \\
\text { Escalona et al. } \\
\text { (2017). }\end{array}$ \\
\hline $\begin{array}{l}\text { Colony } \\
\text { hybridization }\end{array}$ & $\begin{array}{l}\text { This method is based upon direct } \\
\text { plating of sample material on a } \\
\text { nutrient medium. The resulting } \\
\text { colonies are transferred onto } \\
\text { nylon membranes and hybridized } \\
\text { with DNA digoxigenin-labeled } \\
\text { oligoprobes to detect genes } \\
\text { associated to pathogenicity and/or } \\
\text { species-specific. It allows bacterial } \\
\text { species enumeration. }\end{array}$ & $\begin{array}{l}\text { Methods require significant } \\
\text { training. Colony hybridization } \\
\text { is a slow and technically } \\
\text { demanding method. }\end{array}$ & $\begin{array}{l}\text { Suffredini et al. } \\
\text { (2014). }\end{array}$ \\
\hline
\end{tabular}




\begin{tabular}{|c|c|c|c|}
\hline $\begin{array}{l}\text { Diagnostic } \\
\text { Method }\end{array}$ & Relevant applications & Limitations & $\begin{array}{l}\text { Relevant } \\
\text { reference }\end{array}$ \\
\hline LAMP & $\begin{array}{l}\text { LAMP assays (loop-mediated } \\
\text { isothermal amplification) are } \\
\text { a singlestep procedure that } \\
\text { requires four to six primers that } \\
\text { bind laterally to distinct sites } \\
\text { using stranddisplacement DNA } \\
\text { polymerases. Typically, LAMP takes } \\
\text { place under isothermal conditions. } \\
\text { Because of the numbers of primers } \\
\text { used, they permit extremely } \\
\text { specific amplification. Amplified } \\
\text { DNA products can be detected by } \\
\text { turbidimeter, gel electrophoresis, } \\
\text { lateral flow dipstick, as well as } \\
\text { the naked eye. Assay for LAMP } \\
\text { have been developed for both V. } \\
\text { vulnificus and } V \text {. parahaemolyticus. } \\
\text { LAMP is a sensitive, rapid, and } \\
\text { cost-effective method that can be } \\
\text { deployed in the field using portable } \\
\text { equipment. }\end{array}$ & $\begin{array}{l}\text { Requires specialist training } \\
\text { for use. Primer design can } \\
\text { be technically challenging. } \\
\text { Because LAMP is a highly } \\
\text { sensitivity method and } \\
\text { produces very large amounts } \\
\text { of amplified DNA it is } \\
\text { susceptible to false positive } \\
\text { reactions because of cross- } \\
\text { contamination events in the } \\
\text { laboratory. LAMP can be less } \\
\text { sensitive than PCR to inhibitors } \\
\text { in case of complex samples. }\end{array}$ & $\begin{array}{l}\text { Yamazaki et al. } \\
\text { (2008). } \\
\text { Han et al. (2011). }\end{array}$ \\
\hline MALDI-TOF & $\begin{array}{l}\text { MALDI-TOF (matrix-assisted laser } \\
\text { desorption/ionization time } \\
\text { of-flight) mass spectrometry } \\
\text { for the rapid identification of Vibrio } \\
\text { spp. Sample preparation is simple } \\
\text { and bacterial species identification } \\
\text { is rapid and automated. }\end{array}$ & $\begin{array}{l}\text { Start-up costs of purchasing a } \\
\text { MALDI-Tof can be expensive. } \\
\text { Requires specialist training for } \\
\text { use. Requires databases for } \\
\text { species identification. }\end{array}$ & $\begin{array}{l}\text { Dieckmann, } \\
\text { Strauch, \& Alter. } \\
\text { (2010). }\end{array}$ \\
\hline
\end{tabular}

\subsection{CLIMATE CHANGE}

There is increasing concern regarding the role of climate change in mediating the spread of waterborne and foodborne infectious diseases, such as those caused by vibrios. A number of physical manifestations of climate change are likely to play a significant role in increasing risks associated with pathogenic vibrios (BakerAustin et al., 2012), and in particular non-cholera vibrios such as $V$. vulnificus, $V$. parahaemolyticus, and non-O1 V. cholerae (Baker-Austin et al., 2017). The recent change in sea temperature is considered as the most pervasive and severe cause of impact in coastal ecosystems worldwide (Halpern et al., 2008), particularly in light of recent observations demonstrating significant warming in over $70 \%$ of the world's coastlines (Lima and Wethey, 2012). Climate change plays a significant role in determining the prevalence as well as growth dynamics of many bacterial pathogens, and many diseases are expected to increase in range and severity with projected climate change (Koelle et al., 2009). Non-cholera vibrios such as $V$. 
vulnificus and $V$. parahaemolyticus grow in warm, low salinity waters, and their growth is proportional to ambient environmental temperatures. Vibrios have some of the fastest replication times of all known and studied bacteria, making them highly responsive to favourable environmental stimuli (Baker-Austin et al., 2016). There is now much greater understanding regarding the role of climate change, and in particular anomalous warming events in driving vibriosis outbreaks and associated human health risks. Worldwide, oceanic warming has significantly increased the areas suitable for pathogenic vibrios to proliferate and cause human health illness (Watts et al., 2019). Infections from these pathogens are now being reported in areas with little or no previous incidence, with clear implications for future risk. These include shellfish-associated outbreaks of $V$. parahaemolyticus in Alaska (McLaughlin et al., 2005), and Chile (Martinez-Urtaza et al., 2010), and non-cholera vibrio infections reported in Northern Europe during heatwave events (Baker-Austin et al., 2012; Baker-Austin et al., 2016). In 2018, the first outbreak of non-O1/nonO139 Vibrio cholerae infections linked to consumption of herring eggs were reported in British Columbia, Canada. Other extreme climatic events have also been linked to an increase in reported vibrio infections. Data from the US CDC revealed a sharp increase in vibrio wound infections following Hurricane Katrina making landfall on the Gulf coast of the United States of America in August 2005 (Anon, 2005).

There is a growing body of evidence to indicate that climatic warming may allow certain vibrio strains to emerge in new areas. For instance, a highly pathogenic variant of $V$. parahaemolyticus belonging to the clonal complex ST36 and termed the Pacific Northwest strain emerged on the Northeast coast of the United States of America during the unusually warm spring of 2012 (Newton et al., 2014). As such, these rapid and localised warming events may represent an important epidemic ignition that allows particular strains to emerge from environmental sources, leading to outbreaks. Oceanic warming has also been linked to the successful dissemination of outbreak strains of $V$. parahaemolyticus in Galicia, NW Spain over the last 2 decades (Martinez-Urtaza et al., 2018). Few long-term studies in this area exist, somewhat limiting our understanding, thus the emergence of clinical cases is often interpreted as a sporadic event due to exceptional conditions, rather than a response to long-term environmental change (Baker-Austin et al., 2012). However, recent analysis of the long-term plankton datasets in the North Sea have demonstrated a clear transition during the 1980's, with the bacterial community becoming dominated by vibrios (Vezzulli et al., 2012). These data are striking as the transition appears to correspond closely with the temporal warming trends in the area, and further corroborates the emergence of marine-borne vibriosis, in particular at high latitudes. Future ocean acidification and warming linked to climate change is another physiochemical stressor to oceanic organisms. Ocean acidification has been implicated in increased $V$. parahaemolyticus growth in 
certain shellfish species (Hernroth et al., 2015), potentially increasing public health risks.

TABLE 5. Climate suitability for vibrio outbreaks. Changes observed in the percentage of suitable areas from the 1980 s to the present data.

\begin{tabular}{lccc}
\hline Country & Warming trend & Ranking & Region \\
\hline Lebanon & 1.50351 & 1 & Mediterranean \\
Israel & 1.4186 & 2 & Mediterranean \\
$\begin{array}{l}\text { Syrian Arab } \\
\text { Republic }\end{array}$ & 1.38938 & 3 & Mediterranean \\
Netherlands & 1.03714 & 7 & North Sea \\
Belgium & 0.988717 & 9 & North Sea \\
Portugal & 0.971618 & 10 & Atlantic \\
Lithuania & 0.907568 & 11 & Baltic Sea \\
Germany & 0.852456 & 13 & Baltic Sea \\
Poland & 0.832356 & 15 & Baltic Sea \\
France & 0.693102 & 23 & Atlantic \\
\hline
\end{tabular}

The emergence of non-cholera vibrio diseases, particularly in geographical regions with a lack of longterm epidemiological datasets provides startling practical challenges to the vibrio research community. Improvements in the epidemiology, and in particular the surveillance and reporting of these pathogens is critical, principally in geographical regions that lack a centralised and coordinated monitoring and surveillance system for vibrios. Countries with enhanced and well embedded surveillance systems, such as the COVIS system in the United States of America (Newton et al., 2012), may represent a useful blueprint for other countries to use.

\subsection{DEMOGRAPHIC DRIVERS}

Population changes in industrialized countries may modulate certain risks related to the likelihood of vibrio infections from seafood. According to the United Nations, a significant ageing of the world population is expected in the next several decades and is projected for most regions of globe. An aging demographic may increase the likelihood and severity of infections for a larger percentage of the 
population globally. Globally, the fraction of the population aged 65 years or over increased from 6 per cent in 1990 to 9 per cent in 2019. That proportion is projected to rise further to 16 per cent by 2050 , so that one in six people in the world will be aged 65 years or over (United Nations, 2019). All continental regions will see an increase in the size of their older population between 2019 and 2050 (United Nations, 2019). Importantly, infections with $V$. vulnificus septicaemia show greatest risk for individuals with pre-existing conditions, often linked to age (Jones and Oliver 2009). Previous studies have indicated that individuals with compromised immune systems or chronic liver disease such as cirrhosis are up to 80 times more likely than healthy individuals to develop $V$. vulnificus primary septicaemia (Anon, 1993; Baker-Austin and Oliver 2018). Recent epidemiological data, such as liver cirrhosis trends in the United States of America (Scaglione et al., 2015), show a similar correlation between gender and age to that of observed V. vulnificus cases, with a disproportionate rate of cirrhosis in males and in older age groups (e.g. $>40$ years old). Projections to 2025, the alcohol per capita consumption (15+ years) is expected to continue to increase in half of the WHO regions, potentially greatly increasing risk. Likewise increasing liver cirrhosis in women (Scmucke et al., 2005), increasing liver disease in the elderly and hepatitis infections (Scaglione et al., 2015) should also be considered. Other demographic drivers that can be considered include the changing middle class (WHO, 2014) arising from rapidly rising economies in China and India where food preference may be changing and thus influencing the demand of aquaculture production, both domestically and globally. These increasing exposures are likely drivers of risk for vibriosis in the future. Considerations may also include age-dependent behaviours influencing risk of infections. 


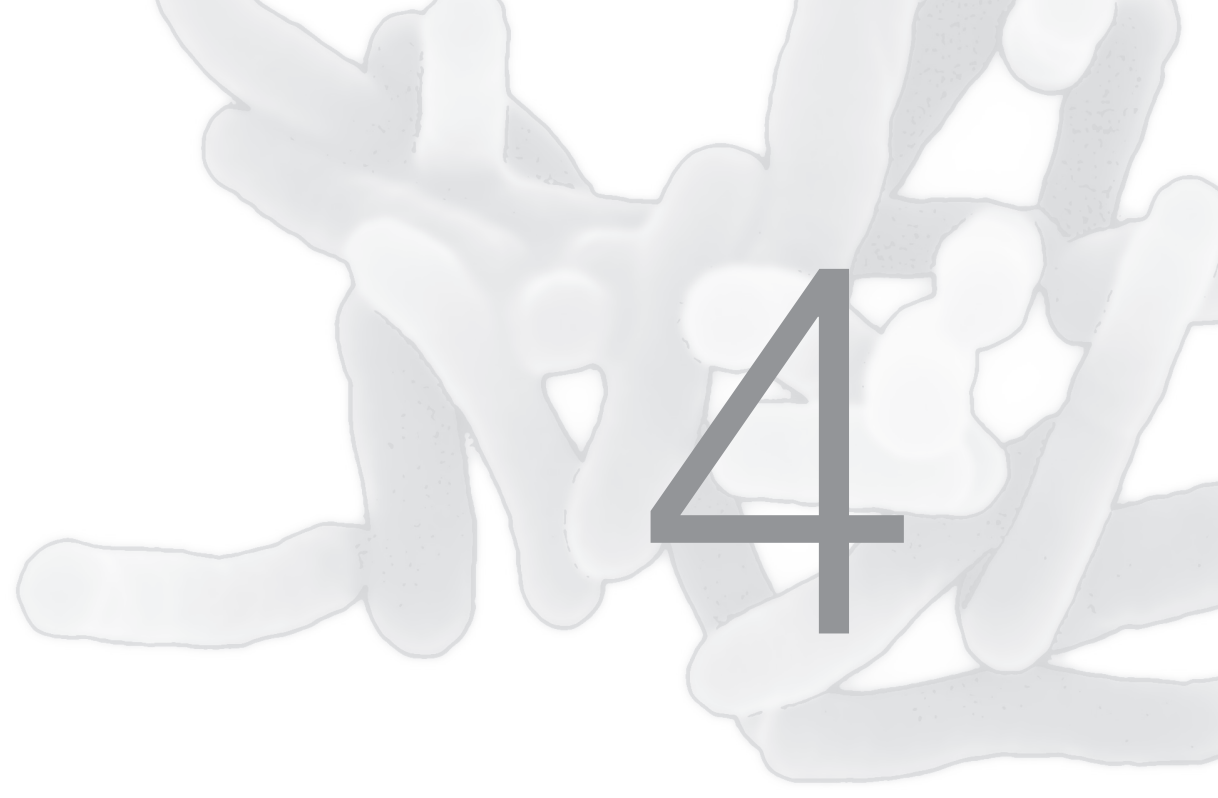

\section{Conclusions and recommendations}

Globally, raw shellfish products, especially oysters, represent the most common foodborne source of vibriosis (Newton et al., 2012; Baker-Austin et al., 2018). It is clear that in the last decade our understanding of these organisms, the risks that they pose, as well as their management continues to evolve. Considering these continuous discussions, a JEMRA expert meeting on $V$. parahaemolyticus and $V$. vulnificus was held at Cefas, Weymouth, the United Kingdom, 13-15 May 2019. The meeting reviewed and updated the existing risk assessment models/tools of $V$. parahaemolyticus and V. vulnificus that could be used to address a range of risk management questions in a number of different regions. Several important areas where addressed and discussed during this expert workshop (summarised in Figure 2). The experts concurred that the basic scientific outputs underpinning previous risk assessment endeavours were still valid; however, a range of important development have occurred in the last decade that are noteworthy and have direct impacts on the risk assessment of these important human pathogens.

These developments are complex and often multifaceted, and draw on aspects related to microbiology, genomics, risk assessment, epidemiology, climate sciences and oceanography. Firstly, the emergence of highly pathogenic strains, in particular the PNW (ST36) V. parahaemolyticus complex have caused infections in new areas and in regions where these diseases have not been observed before. The pandemic spread of these bacteria provides new challenges to the risk assessment community. Secondly, in response to climate change, there has been a significant 
geographical spread regarding when and where these seafood-associated vibrio infections have been reported, with a general trend in the poleward spread of $V$. parahaemolyticus and V. vulnificus cases. We are now observing seafood-related infections in traditionally non-endemic areas such as the NE United States of America, Spain, and South America, among others. Demographic considerations are also important. Globally, an increased at-risk population, increased population densities in coastal regions and improvements in diagnosis of infections may also have played a role in accentuating reported cases. A number of important datagaps still exist, notably the availability of high quality epidemiology data from geographically diverse regions (other than the United States of America), which probably represents the most pressing current limitation. New approaches for best practice, such as high-pressure treatment, harvesting curfews, relaying and temperature controls appear to offer cost effective approaches for reducing human health risks postharvest. Finally, a range of new methods, such as those utilising genomics and satellite imagery provide novel means of building on previous risk assessment exercises for these important foodborne pathogens. The remotesensing based approaches have proved invaluable in understanding the conditions that can drive outbreaks of foodborne disease, and potentially offer the capability to predict future outbreak conditions in near real-time. The development of WGS allows us to understand the genomic and biological architecture of pathogens that can cause disease, reconstruct the emergence, dispersal, and even the evolution of these bacteria. The unparalleled resolution of sequencing methods has enormous practical applications whilst inferring mechanisms of transmission, unravelling the evolution of strains, as well as pinpointing outbreaks for risk management purposes.

Several recommendations were noted during this meeting. These include the following: 1) The establishment of systems for epidemiological data collection at a regional, national and international level; 2) A systematic review of the efficacy of post-harvest processing treatments and pre and post-harvest interventions in risk mitigation - including appropriate cost/benefit analysis; 3) verification of the efficacy of remote sensing, satellite approaches and WGS to predict periods of elevated risks and to better control those risks. The translation and integration of these novel methods into practical and tractable risk control measures is also required; 4) a thorough assessment of laboratory methods utilised to study these bacteria is urgently required. This could take the form of guidance documents or good practice documents that outline and describe in detail the most appropriate methods applicable for the isolation, growth, detection and enumeration of these bacterial pathogens across environmental, clinical and food samples. Consensus on appropriate molecular targets and testing approaches such as those applied to shellfish (for example $t d h / t r h$ in $V$. parahaemolyticus) potentially represents the most important technical issue that should be considered at his point. 
FIGURE 2. Major microbiological, environmental and human-related factors responsible for driving vibriosis risks associated with bivalve shellfish.

Relevant subjects in MRA 20

2. Pathogenicity

3. Factors relevant to the fate of $V$. parahaemolyticus and $V$. vulnificus

3.1. Water temperature

3.2. Salinity

3.3. Other environmental factors

3.4 Seafood of concern 3.5 Preharvest and post harvest practices

4. Evaluation and application of existing risk assessment tools

4.2 Evaluation of the models for vibrio concentration at harvest 4.3 Evaluation of the vibrio growth rate models 4.4. Evaluation of dose response models

5. Method for isolation, identification, and determination of pathogenic potentials of shellfish-associated Vibrio parahaemolyticus, Vibrio vulnificus
Major factors in the human and natural environment possibly affecting emergence and spread of Infections by Vibrio parahaemolyticus and Vibrio vulnificus

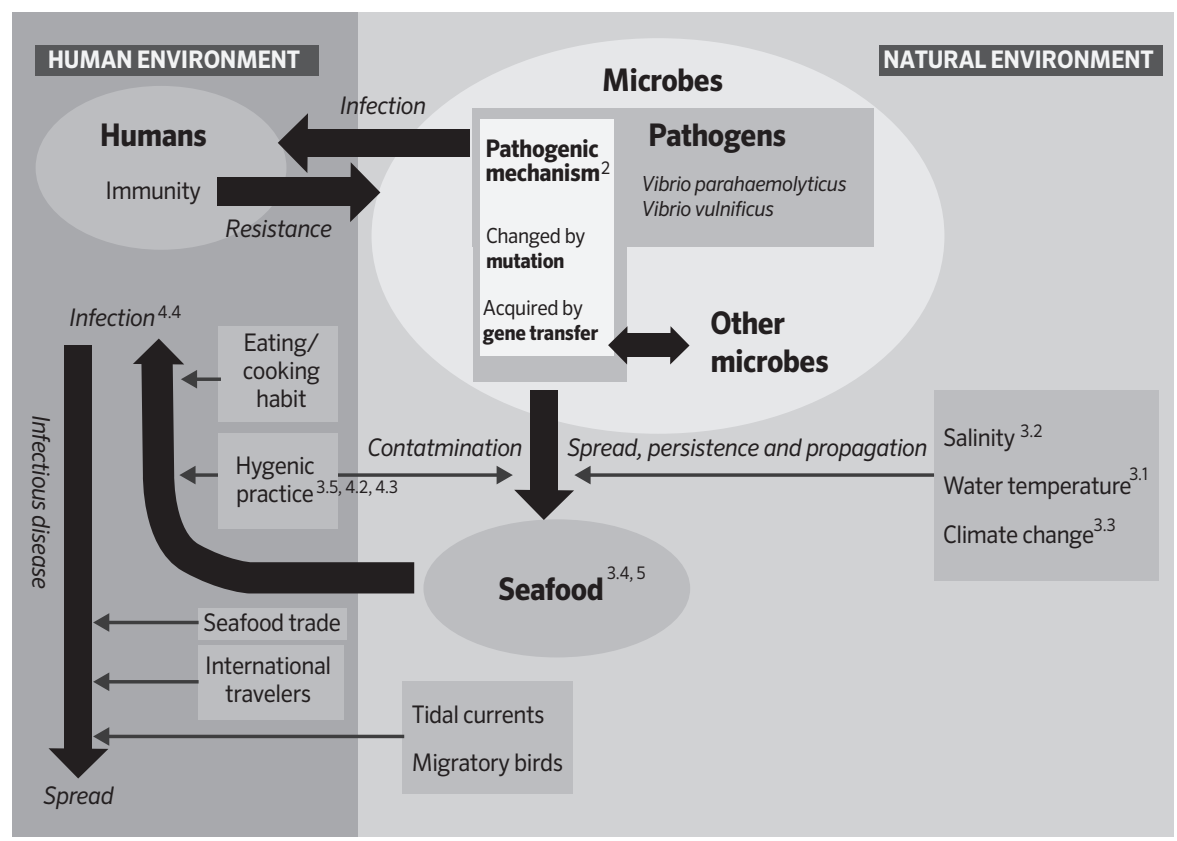

Note: Sections of MRA20 are referenced (left) to indicate the corresponding position on the figure 


\section{References}

Abanto, M., Gavilan, R.G., Baker-Austin, C., Gonzalez-Escalona, N. \& MartinezUrtaza. J. 2020. Global expansion of Pacific Northwest V.parahaemolyticus sequence type 36. Emerging Infectious Diseases, 26(2): 323-326. doi:10.3201/eid2602.190362.

Amaro, C., Sanjuán, E., Fouz, B., Pajuelo, D., Lee, C., Hor, L. \& Barrera, R. 2015. The fish pathogen Vibrio vulnificus Biotype 2: epidemiology, phylogeny and virulence factors involved in warm-water vibriosis. Microbiology Spectrum, 3: 1-23.

Ama, A.A., Hamdy, M.K. \& Toledo, R.T. 1994. Effect of heating, $\mathrm{pH}$ and thermoradiation on inactivation of V. vulnificus. Food Microbiology, 11(3): 215-227.

American Water Works Association. 1997. Vibrio. Standard Methods for the Examination of Water and Wastewater 9260 Detection of Pathogenic Bacteria (also available at https://doi.org/10.2105/SMWW.2882.201).

Andrews, L., Jahncke, M. \& Mallikarjunan, K. 2003. Low dose gamma irradiation to reduce pathogenic Vibrios in live oysters (Crassostrea virginica). Journal of Aquatic Food Product Technology, 12(3): 71-82.

Andrews, L.S., Park, D.L. \& Chen, Y.P. 2000. Low temperature pasteurization to reduce the risk of vibrio infections from raw shell-stock oysters. Food Additives and Contaminants, 17: 787-791.

Annick Robert-Pillot, Dominique Hervio-Heath \& Marie-Laure Quilici. 2020. Unpublished data. Institute Pasteur, France; Institut Français de Recherche pour L'exploitation de la Mer (Ifremer), France.

Anonymous. 1993. Vibrio vulnificus infections associated with raw oyster consumption. Morbidity and Mortality Weekly Reports, 42: 405-407.

Anonymous. 1998. Outbreak of V. parahaemolyticus Infections Associated with eating raw oysters - Pacific Northwest, 1997. http://www.cdc.gov/mmwr/preview/ mmwrhtml/00053377.htm.

Anonymous. Vibrio illnesses after Hurricane Katrina - multiple states, August-September 2005 Morbidity and Mortality Weekly Reports, 54: 928-931.

Anonymous. 2009. Preliminary FoodNet data on the incidence of infection with pathogens transmitted commonly through food - 10 states, 2008. Morbidity and Mortality Weekly Reports, 58(22): 333-337.

Anonymous. 2017a. Microbiological Monitoring of bivalve mollusc harvesting areas guide to good practice: technical application (issue 2017). https://eurlcefas.org/ media/13973/gpg_issue-6-fianl-170117.pdf.

Anonymous. 2017b. ISO 21872-1:2017. Microbiology of the food chain - Horizontal method for the determination of Vibrio spp. - Part 1: Detection of potentially enterophatogenic Vibrio parahaemolyticus, Vibrio cholerae and Vibrio vulnificus. https://www.iso.org/standard/74112.html. 
Anonymous. 2020a. Cholera and other Vibrio illness Surviellance (COVIS). https://www. cdc.gov/vibrio/surveillance.html.

Anonymous. 2020b. Foodborne Diseases Active Surveillance Network (FoodNet). https://www.cdc.gov/foodnet/index.html.

Aznar, R., Ludwig, W., Amann, R.I. \& Schleifer, K.H. 1994. Sequence determination of rRNA genes of pathogenic Vibrio species and whole-cell identification of $V$. vulnificus with rRNA-targeted oligonucleotide probes. International Journal of Systematic Bacteriology, 44: 330-337

Baker-Austin, C., McArthur, J.V., Lindell, A., Wright, M., Gooch, J., Warner, L., Oliver, J. \& Stepanauskas, R. 2009. Widespread antibiotic resistance in the marine pathogen Vibrio vulnificus. Microbial Ecology, 57: 151-159.

Baker-Austin, C., Stockley, L., Rangdale, R. \& Martinez-Urtaza, J. 2010. Environmental occurrence and clinical impact of V. vulnificus and V.parahaemolyticus: A European perspective. Environmental Microbiology Reports, 2: 7-18.

Baker-Austin, C., Trinanes, J., Hartnell, R., Taylor, N., Siitonen, A. \& Martinez-Urtaza, J. 2012. Emerging Vibrio risk at high latitudes in response to ocean warming. Nature Climate Change, 3: 73-77.

Baker-Austin, C., Trinanes, J.A., Gonzalez-Escalona, N. \& Martinez-Urtaza, J. 2016. Non-cholera vibrios - the microbial barometer of climate change. Trends in Microbiology, 25(1): 76-84.

Baker-Austin, C., Oliver, J.D., Alam, M., Ali, A., Waldor, M.A., Qadri, F. \& MartinezUrtaza, J. 2018. Vibrio spp. infections. Nature Disease Primers, 4: 8.

Baker-Austin, C., \& Oliver, J.D. 2018. V. vulnificus - new insights into a deadly opportunistic pathogen. Environmental Microbiology, 20(2): 423-430.

Baker-Austin, C., Jenkins, C., Dadzie, J., Mestanza, O., Delgado, E., Powell, A., Bean, T. \& Martinez-Urtaza, J. 2020. Genomic epidemiology of domestic and travelassociated of seafood-related V. parahaemolyticus infections in the UK, 2008-2018. Food Control, 115: 107244. doi: 10.1016/j.foodcont.2020.107244.

Bastías, R., Higuera, G., Sierralta, W. \& Espejo, R. 2010. A new group of cosmopolitan bacteriophages induce a carrier state in the pandemic strain of V.parahaemolyticus. Environmental Microbiology, 12: 990-1000.

Bej, A.K., Patterson, D.P., Brasher, C.W., Vickery, M.C., Jones, D.D., \& Kaysner, C.A. 1999. Detection of total and hemolysin-producing Vibrio parahaemolyticus in shellfish using multiplex PCR amplification of $t$, $t d h$ and trh. Journal of Microbiological Methods, 36(3): 215-225.

Berlin, D.L., Herson, D.S., Hicks, D.T. \& Hoover, D.G. 1999. Response of pathogenic Vibrio species to high hydrostatic pressure. Applied and Environmental Microbiology, 65(6): 2776-2780. 
Bhoopong, P., Palittapongarnpim, P., Pomwised, R., Kiatkittipong, A., Kamruzzaman, M., Nakaguchi, Y., Nishibuchi, M., Ishibashi, M. \& Vuddhakul, V. 2007. Variability of properties of $V$. parahaemolyticus strains isolated from individual patients. Journal of Clinical Microbiology, 44: 1544-1550.

Bisharat, N., Cohen, D.I., Harding, R.M., Falush, D., Crook, D.W., Peto, T., \& Maiden, M.C. 2005. Hybrid Vibrio vulnificus. Emerging Infectious Diseases, 11(1): 30-35. (also available from: https://doi.org/10.3201/eid1101.040440).

Bowley, J., Baker-Austin, C., Porter, A., Hartnell, R.H. \& Lewis, C. 2020. Oceanic hitchhikers-assessing pathogen risks from marine microplastic. Trends in Microbiology, 29(2): 107-116. https://doi.org/10.1016/j.tim.2020.06.011.

British Columbia Centre for Disease Control. 2018. Laboratory Trends - A Report from the BCCDC public health laboratory. (also available from: http://www.bccdc.ca/ resource-gallery/Documents/Statistics\%20and\%20Research/Statistics\%20and\%20 Reports/Labs/August\%202018\%20Laboratory\%20Trends.pdf).

Campbell, M.S., \& Wright, A.C. 2003. Real-time PCR analysis of Vibrio vulnificus from oysters. Applied and Environmental Microbiology, 69(12): 7137-7144.

Caro-Castro, J., Mestanza, O., Quino, W., \& Gavilán R.G. 2020. Diversidad molecular de variantes patogénicas de Vibrio parahaemolyticus en el Perú. The Peruvian Journal of Experimental Medicine and Public Health Within The National Political Context, 37(2): 270-5.

Carda-Diguez, M., Silva-Hernndez, F., Hubbard, T., Chao, M., Waldor, M. \& Amaro, C. 2018. Comprehensive identification of Vibrio vulnificus genes required for growth in human serum. Virulence, 9: 981-993.

CDC. 2021. The Cholera and Other Vibrio Illness Surveillance (COVIS) System. Atlanta, GA: US Department of Health and Human Services, CDC. Data extracted 01/14/2021.

Ceccarelli, D., Amaro, C., Romalde, J., Suffredini, E. \& Vezzulli, L. 2019. Vibrio species. Doyle,M., Diez-González,F., and Hill,C. (eds), Food Microbiology: Fundamentals and Frontiers. ASM Press. Washington. DC

Chen, C. Y., Wu, K. M., Chang, Y. C., Chang, C. H., Tsai, H. C., Liao, T. L., Liu, Y. M., Chen, H. J., Shen, A. B., Li, J. C., Su, T. L., Shao, C. P., Lee, C. T., Hor, L. I., \& Tsai, S. F. 2003. Comparative genome analysis of Vibrio vulnificus, a marine pathogen. Genome Research, 13(12): 2577-2587. (also available from: https://doi.org/10.1101/ gr.1295503).

Chowdhury, G., Ghosh, S., Pazhani, P.G., Paul, B.K., Paul, B.K., Maji, D., Mukhopadhyay, A.K. \& Ramamurthy, T. 2013. Isolation and characterisation of pandemic and nonpandemic strains of Vibrio parahaemolyticus from an outbreak of diarrhea in North 24 Paragans, West Bengal, India. Foodborne Pathogens \& Disease, 10: 338-342. 
Córdova, J.L., Astorga, J., Silva, W. \& Riquelme, C. 2002. Characterization by PCR of Vibrio parahaemolyticus isolates collected during the 1997-1998 Chilean outbreak. Biological Research, 35: 3-4.

Croci, L., Suffredini, E., Cozzi, L. \& Toti, L. 2002. Effects of depuration of molluscs experimentally contaminated with Escherichia coli, V. cholerae $\mathrm{O} 1$ and $V$. parahaemolyticus. Journal of Applied Microbiology, 92: 460-465.

DePaola, A., Hopkins, L.H., Peeler, J.T., Wentz, B. \& McPhearson, R.M. 1990. Incidence of Vibrio parahaemolyticus in U.S. coastal waters and oysters. Applied and Environmental Microbiology, 56: 2299-2302.

Dieckmann, R., Strauch, E., \& Alter, T. 2010. Rapid identification and characterization of Vibrio species using whole-cell MALDI-TOF mass spectrometry. Journal of Applied Microbiology, 109(1), 199-211. (also available from: https://doi. org/10.1111/j.1365-2672.2009.04647.x).

FAO/WHO. 2003. Hazard characterization for pathogens in food and water: guidelines. Microbiological Risk Assessment Series No. 3. Rome. (also available from: http:// www.fao.org/tempref/docrep/fao/006/y4666E/y4666E00.pdf).

FAO/WHO. 2005a. Risk Assessment of V. vulnificus in Raw Oysters. Microbiological Risk Assessment Series No. 8. Rome. (also available from: http://www.who.int/ foodsafety/publications/micro/mra8.pdf).

FAO/WHO. 2005b. Risk assessment of choleragenic Vibrio cholerae O1 and O139 in warm-water shrimp in international trade. Interpretative Summary and Technical Report. Microbiological Risk Assessment Series No. 9. Rome. (also available from: http://www.fao.org/3/a0253e/a0253e.pdf).

FAO/WHO. 2011. Risk assessment of V. parahaemolyticus in seafood: interpretative summary and technical report. Microbiological Risk Assessment Series No. 16. Rome. (also available from: http://apps.who.int/iris/handle/10665/44566).

FAO/WHO. 2016. Selection and application of methods for the detection and enumeration of human-pathogenic halophilic Vibrio spp. in seafood. Microbiological Risk Assessment Series, No. 22. Rome. (also available from: https://www.who.int/ publications/i/item/9789241565288).

FAO/WHO. 2020. Risk assessment tools for V. parahaemolyticus and V. vulnificus associated with seafood. Microbiological Risk Assessment Series No. 20. Rome. (also available from: https://apps.who.int/iris/handle/10665/330867).

Faruque, S.M. \& Nair, G.B. 2006. Epidemiology. In F.L. Thompson, B. Austin, J. Swings, eds. The Biology of Vibrios, pp383-398. Washington D.C., ASM Press.

First Nations Health Authority. 2018. Update: Illness associated with herring eggs Vancouver Island.(also available from:https://www.fnha.ca/about/news-and-events/ news/update-illness-associatedwith-herring-eggs-vancouver-island). 
Froelich, B., Gonzalez, R., Blackwood, D., Lauer, K. \& Noble., R. 2019. Decadal monitoring reveals an Increase in Vibrio spp. concentrations in the Neuse River estuary, North Carolina, USA. PLoS ONE, 14(4): 1-25. doi:10.1371/journal. pone. 0215254 .

Fuenzalida, L., Hernandez, C., Toro, J., Rioseco, M.L., Romero, J. \& Espejo, R.T. 2005. Vibrio parahaemolyticus in shellfish and clinical samples during two large epidemics of diarrhoea in southern Chile. Environmental Microbiology, 8(4): 675-83. doi: 10:10111/j.1462-2920.2005.00946.X.

Fujino, T., Okuno, Y., Nakada, D., Aoyama, A., Fukai, K., Mukai, T. \& Ueho, T. 1953. On the bacterial examination of Shirasufood poisoning. Medical Journal of Osaka University, 4: 299-304.

Garcia, K., Torres, R., Uribe, P., Hernandez, C., Rioseco, M.L., Romero, J. \& Espejo, R.T. 2009 Dynamics of clinical and environmental Vibrio parahaemolyticus strains during seafood-related summer diarrhea outbreaks in southern Chile. Applied and Environmental Microbiology, 75(23): 7482-7487. doi: 10.1128/AEM 01662-09.

González-Escalona, N., Cachicas, V., Acevedo, C., Rioseco, M.L., Vergara, J.A., Cabello, F., Romero, J. \& Espejo, R.T. 2005. Vibrio parahaemolyticus diarrhea, 1998-2004. Emerging Infectious Disease, 11(1): 129-131. doi: 10.3201/eid1101-0490762.

González-Escalona, N., J. Martinez-Urtaza, J. Romero, R.T. Espejo, L.A. Jaykus, \& A. DePaola. 2008. Determination of molecular phylogenetics of Vibrio parahaemolyticus strains by multilocus sequence typing. Journal of Bacteriology, 190: 2831-2840.

González-Escalona, N., Jolley, K.A., Reed, E. \& Martinez-Urtaza, J. 2017. Defining a core genome multilocus sequence typing scheme for the global epidemiology of Vibrio parahaemolyticus. Journal of Clinical Microbiology, 55(6): 1682-1697. (also available from: https://doi.org/10.1128/JCM.00227-17).

Grimes, D.L., Ford, T.E., Colwell, R.R., Baker-Austin, C., Martinez-Urtaza, J. \& Capone, D.G. 2014. Viewing marine bacteria, their activity and response to environmental drivers from orbit. Microbial Ecology, 67(3): 1489-1500.

Guin, S., Saravanan, M., Anjay, Chowdhury, G., Pazhani, G.P., Ramamurthy, T. \& Das, S.C. 2019. Pathogenic Vibrio parahaemolyticus in diarrheal patients, fish and aquatic environments and their potential for inter-source transmission. Heliyon, 5: e01743.

Halpern, B.S. 2008. A global map of human impact on marine ecosystems. Science, 319: 948-952.

Han, F., Wang, F. \& Ge, B. 2011. Detecting potentially virulent Vibrio vulnificus strains in raw oysters by quantitative loop-mediated isothermal amplification. Applied and Environmental Microbiology, 77(8): 2589-2595. (also available from: https://doi. org/10.1128/AEM.02992-10). 
Hartnell, R., Stockley, L., Keay, W., Rosec, J.-P., Hervio-Heath, D., Van den Berg, H., Leoni, F., Ottaviani, D., Henigman, U., Denayer, S., Serbruyns, B., Georgsson, F., Krumova-Valcheva, G., Gyurova, E., Blanco, C., Copin, S., Strauch, E., Wieczorek, K., Lopatek, M., Britova, A., Hardouin, G., Lombard, B., In't Veld, P., Leclercq, A. \& Baker-Austin, C. 2018. A pan-European ring trial to validate an International Standard for detection of $V$. cholerae, $V$. parahaemolyticus and $V$. vulnificus in seafoods. International Journal of Food Microbiology, 288: 58-65.

Heitmann, I., Jofre, L., Hormazabal, J.C., Olea, A., Vallebuona, C.L. \& Valdes, C.1. 2005. Revisión y recomendaciones para el manejo de diarrea por Vibrio parahaemolyticus. Revista chilena de infectología, 22(2): 131-140.

Hernández-Cabanyero, C. \& Amaro, C. 2020. Phylogeny and life cycle of the zoonotic pathogen Vibrio vulnificus. Environmental Microbiology, 22(10): 4133-4148.

Hernández-Cabanyero, C., Lee, C.T., Tolosa-Enguis, V., Sanjuán, E., Pajuelo, D., Reyes-López, F., Tort, L. \& Amaro, C. 2019. Adaptation to host in Vibrio vulnificus, a zoonotic pathogen that causes septicemia in fish and humans. Environmental Microbiology, 21: 3118-3139.

Hernroth, B., Krång, A.S. \& Baden, S. 2015. Bacteriostatic suppression in Norway lobster (Nephrops norvegicus) exposed to manganese or hypoxia under pressure of ocean acidification. Aquatic Toxicology, 159: 217-224. doi: 10.1016/j.aquatox.2014.11.025.

Hill, W.E., Keasler, S.P., Trucksess, M.W., Feng, P., Kaysner, C.A. \& Lampel, K. A. 1991. Polymerase chain reaction identification of Vibrio vulnificus in artificially contaminated oysters. Applied and Environmental Microbiology, 57(3): 707-711. (also available from: https://doi.org/10.1128/AEM.57.3.707-711.1991).

Hollis, D.G., Weaver, R.E., Baker C.N. \& Thornsberry, C. 1976. Halophilic Vibrio species isolated from blood cultures. Journal of Clinical Microbiology, 3(4): 425-431.

Honda, T., Ni, Y. \& Miwatani, T. 1988. Purification and characterization of a hemolysin produced by a clinical isolate of Kanagawa phenomenon-negative $V$. parahaemolyticus and related to the thermostable direct hemolysin. Infection and Immunity, 56: 961-965.

Honda, T. \& Iida, T. 1993. The pathogenicity of V. parahaemolyticus and the role of the thermostable direct haemolysin and related haemolysins. Reviews in Medical Microbiology, 4: 106-113.

Iwamoto, M., Ayers, T., Mahon, B. \& Swerdlow, D. 2010. Epidemiology of seafoodassociated infections in the United States. Clinical Microbiology Reviews, 23(2): 399-411.

ISSC. 2017. ISSC / FDA National V. parahaemolyticus workshop. www.issc.org.

Jeong, H.-G. \& Satchell, K.J.F. 2012. Additive function of Vibrio vulnificus MARTX(Vv) and VvhA cytolysins promotes rapid growth and epithelial tissue necrosis during intestinal infection. PLoS Pathogen, 8(3): e1002581. 
Johnson, C.N., Flowers. A.R., Young, V.C., Gonzalez-Escalona, N., DePaola, A.,

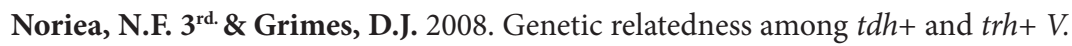
parahaemolyticus cultured from Gulf of Mexico oysters (Crassostrea virginica) and surrounding water and sediment. Microbial Ecology, 57: 437-443.

Jones, J.L., Kinsey, T.P., Johnson, L. W., Porsom R., Friedman, B., Curtis, M., Wesighan, P., Schuster, R. \& Bowers, J.C. 2016. Effects of intertidal harvest practices on V. parahaemolyticus and V. vulnificus levels in oysters. Applied and Environmental Microbiology, 82: 4517-4522.

Jones, J.L., Ludeke, C. H., Bowers, J.C., Garrett, N., Fischer, M., Parsons, M.B., Bopp, C.A. \& DePaola, A. 2012. Biochemical, serological, and virulence characterization of clinical and oyster Vibrio parahaemolyticus isolates. Journal of Clinical Microbiology, 50: 2343-2352. doi: 10.1128/JCM.00196-12.

Jones, M.K. \& Oliver, J.D. 2009. V. vulnificus: Disease and pathogenesis. Infection and Immunity, 77(5): 1723-1733.

Joseph, S.W., Colwell, R.R. \& Kaper, J.B. 1982. V. parahaemolyticus and related halophilic Vibrios. Critical Reviews in Microbiology, 10: 77-124.

Koelle, K. 2009. The impact of climate on the disease dynamics of cholera. Clinical Microbiology and Infection, 15: 29-31.

Lagos, J., Arias, N., Aguayo, C., Ulloa, S., Tognorelli, J., Olivares, B., Parra, B., Campano, C., Ramos, L., Arancibia, M., Gomez, V. Ibañez, M., Becas, M., Sanches, L., Fernandez, A. \& Fernandez, J. 2015. Characterization of Vibrio parahaemolyticus by MLST in Chile. XII Jornadas Científicas. Instituto de Salud Pública de Chile.

Li, Y., Xie, X., Shi, X., Lin, Y., Qiu, Y., Mou, J., Chen, Q., Lu, Y., Zhou, L., Jiang, M., Sun, H., Ma, H., Cheng, J. \& Hu, Q. 2014. Vibrio parahaemolyticus, southern coastal region of China, 20072012. Emerging Infectious Diseases, 20(4): 685-688. doi: 10.3201/eid2004.130744.

Lima, F.P. \& Wethey D.S. 2012. Three decades of high-resolution coastal sea surface temperature reveal more than warming. Nature Communications, 3: 704.

Lin, X., Ran, L., Ma, L., Wang, Z. \& Feng, Z. 2010. Analysis on the cases of infectious diarrhea (rather than cholera, dysentery, typhoid and para typhoid) reported in China. Chinese Journal of Food Hygiene, 23: 385-9.

Liu, X., Chen, Y., Wang, X. \& Ji, R. 2004. Foodborne disease outbreaks in China from 1992 to 2001-national foodborne disease surveillance system. Wei Sheng Yan Jiu, 33: 725-727.

Lydon, K.A., Farrell-Evans, M. \& Jones, J.L. 2015. Evaluation of ice slurries as a control for postharvest growth of Vibrio spp. in oysters and potential for filth contamination. Journal of Food Protection, 78: 1375-1379. 
Lozano-Leon, A., Torres, J., Osorio, C.R. \& Martinez-Urtaza, J. 2003. Identification of $t d h$-positive $V$. parahaemolyticus from an outbreak associated with raw oyster consumption in Spain. FEMS Microbiology Letters, 226: 281-284.

Makino, K., Oshima, K., Kurokawa, K., Yokoyama, K., Uda, T., Tagomori, K., Iijima, Y., Najima, M., Nakano, M., Yamashita, A., Kubota, Y., Kimura, S., Yasunaga, T., Honda, T., Shinagawa, H., Hattori, M. \& Iida, T. 2003. Genome sequence of $V$. parahaemolyticus: a pathogenic mechanism distinct from that of $V$. cholerae. Lancet, 361: 743-749.

Martinez-Urtaza, J., Simental, L., Velasco, D., DePaola, A., Ishibashi, M., Nakaguchi, Y., Nishibuchi, M., Carrera-Flores, D., Rey-Alvarez, C. \& Pousa, A. 2005. Pandemic Vibrio parahaemolyticus O3:K6, Europe. Emerging Infectious Diseases, 11(8): 1319-1320. (also available from: https://doi.org/10.3201/eid1108.050322).

Martinez-Urtaza, J., Lozano-Leon, A., Viña-Feas, A., de Novoa, J. \& Garcia-Martin, O. 2006. Differences in the API 20E biochemical patterns of clinical and environmental Vibrio parahaemolyticus isolates. FEMS Microbiology Letters, 255(1): 75-81.

Martinez-Urtaza, J., Lozano-Leon, A., Varela-Pet, J., Trinanes, J., Pazos, Y. \& GarciaMartin, O.. 2009. Environmental determinants of the occurrence and distribution of Vibrio parahaemolyticus in the rias of Galicia, Spain. Applied and Environmental Microbiology, 74: 265-274.

Martinez-Urtaza, J., Bowers, J.C., Trinanes, J. \& DePaola, A. 2010. Climate anomalies and the increasing risk of V. parahaemolyticus and V. vulnificus illnesses. Food Research International, 43(7): 1780-90.

Martinez-Urtaza, J., Baker-Austin, C., Jones, J.L.J.L., Newton, A.E.A.E., GonzalezAviles, G.D.G.D. \& DePaola, A. 2013. Spread of Pacific Northwest V. parahaemolyticus strain. New England Journal of Medicine, 369: 1573-1574.

Martinez-Urtaza, J., Powell, A., Jansa, J., Rey, J. L., Montero, O.P., Campello, M.G., López, M.J., Pousa, A., Valles, M.J., Trinanes, J., Hervio-Heath, D., Keay, W., Bayley, A., Hartnell, R. \& Baker-Austin, C. 2016a. Pacific Northwest genotypes of V. parahaemolyticus responsible for seafood outbreak in Spain, 2012. SpringerPlus, 5: 87.

Martinez-Urtaza, J., Trinanes, J., Gonzalez-Escalona, N. \& Baker-Austin C. 2016 b. Is El Niño a long distance corridor of waterborne disease? Nature Microbiology, 1: 16018. doi:10.1038/nmicrobiol.2016.18.

Martinez-Urtaza, J., van Aerle, R., Abanto, M., Haendiges, J., Myers, R. A., Trinanes, J., Baker-Austin, C. \& Gonzalez-Escalona, N. 2017. Genomic variation and evolution of $V$. parahaemolyticus ST36 over the course of a transcontinental epidemic expansion. mBio, 8(6): e01425-17. 
Martinez-Urtaza, J., Trinanes, J., Abanto, M., Lozano-Leon, A., Llovo-Taboada, J., Garcia-Campello, M., Pousa, A., Powell, A., Baker-Austin, C. \& GonzalezEscalona, N. 2018. Epidemic dynamics of Vibrio parahaemolyticus illness in a hotspot of disease emergence, Galicia, Spain. Emerging Infectious Diseases, 24(5): 852-859. (also available from: https://doi.org/10.3201/eid2405.171700).

McLaughlin, J.B., DePaola, A., Bopp, C.A., Martinek, K.A., Napolilli, N.P., Allison, C.G., Murray, S.L., Thompson, E.C., Bird, M.M. \& Middaugh, J.P. 2005. Outbreak of V. parahaemolyticus gastroenteritis associated with Alaskan oysters. New England Journal of Medicine, 353: 1463-1470.

Melody, K., Senevirathne, R., Janes, M., Jaykus, L.A. \& Supan, J. 2008. Effectiveness of icing as a postharvest treatment for control of $V$. vulnificus and V.parahaemolyticus in the eastern oyster (Crassostrea virginica). Journal of Food Protection, 71: 1475-1480.

Murciano, C., Lee, C.-T., Fernández-Bravo, A., Hsieh, T.-H., Fouz, B., Hor, L.-I. \& Amaro, C. 2017. MARTX toxin in the zoonotic serovar of Vibrio vulnificus triggers an early cytokine storm in mice. Frontiers in Cellular and Infection Microbiology, 7: $1-19$.

Nair, G.B., Ramamurthy, T., Bhattacharya, S.K., Dutta, B., Takeda, Y. \& Sack, D.A. 2007. Global dissemination of V. parahaemolyticus serotype O3:K6 and its serovariants. Clinical Microbiology Reviews, 20: 39-48.

Newton, A, Kendall, M, Vugia, DJ, Henao, O.L. \& Mahon, B.E. 2012. Increasing rates of vibriosis in the United States, 1996-2010: Review of surveillance data from 2 systems. Clinical Infectious Diseases, 54(suppl 5): S391-S395.

New Zealand ministry of public health. 2019. Website: https://surv.esr.cri.nz/index. php?we_objectID=5096

Nilsson, W.B., Paranjpye, R.N., DePaola, A. \& Strom, M.S. 2003. Sequence polymorphism of the $16 \mathrm{~S}$ rRNA gene of $V$. vulnificus is a possible indicator of strain virulence. Journal of Clinical Microbiology, 41: 442-446.

Nishibuchi, M. \& Kaper, J.B. 1995. Thermostable direct hemolysin gene of $V$. parahaemolyticus: a virulence gene acquired by a marine bacterium. Infection and Immunity, 63: 2093-2099.

Nordstrom, J. L., Vickery, M.C., Blackstone, G.M., Murray, S.L., \& DePaola, A. 2007. Development of a multiplex real-time PCR assay with an internal amplification control for the detection of total and pathogenic Vibrio parahaemolyticus bacteria in oysters. Applied and Environmental Microbiology, 73: 5840-5847.

Oberbeckmann, S., Fuchs, B.M., Meiners, M., Wichels, A., Wiltshire, K.H. \& Gerdts, G. 2012. Seasonal dynamics and modeling of a Vibrio community in coastal waters of the North Sea. Microbial Ecology, 63(3): 543-551. doi: 10.1007/s00248-011-9990-9. 
Okada, N., Iida, T., Park, K.S., Goto, N., Yasunaga, T., Hiyoshi, H., Matsuda, S., Kodama, T. \& Honda, T. 2009. Identification and characterization of a novel type III secretion system in trh-positive Vibrio parahaemolyticus strain TH3996 reveal genetic lineage and diversity of pathogenic machinery beyond the species level. Infection and Immunity, 77: 904-913.

Oliver, J.D. 2006. V. vulnificus. In: Biology of Vibrios. F.L. Thompson, B. Austin, and J. Swing. eds). pp. 349-366. American Society for Microbiology Washington, D.C.

Oliver, J. D. \& Kaper, J.B. 2001. Vibrio species. In: Food Microbiology: Fundamentals and Frontiers. 263-300 M.P. Doyle (eds.),. ASM Press, Washington, DC.

Oliver, J. D. \& Kaper, J.B. 2007. Vibrio species, In: Food Microbiology: Fundamentals and Frontiers, 343-379. M. P. Doyle and L. R. Beuchat (eds.),. ASM Press, Washington, DC.

Ottaviani, D., Leoni, F., Serra, R., Serracca, L., Decastelli, L., Rocchegiani, E., Masini, L., Canonico, C., Talevi, G. \& Carraturo, A. 2012. Nontoxigenic Vibrio parahaemolyticus strains causing acute gastroenteritis. Journal of Clinical Microbiology, 50: 4141-4143.

Parvathi, A., Kumar, H.S., Karunasaga, I. \& Karunasagar, I. 2004. Detection and enumeration of $V$. vulnificus in oysters from two estuaries along the southwest coast of India, using molecular methods. Applied and Environmental Microbiology, 70: 6909-6913.

Pazhana, G.P., Bhowmik, S.K., Ghosh, S., Guin, S., Dutta, S., Rajendran, K., Saha, D.R., Nandy, R.K., Bhattacharya, M.K., Mukhopadhyay, A.K. \& Ramamurthy T. 2014. Trends in the epidemiology of pandemic and non-pandemic strains of Vibrio parahaemolyticus isolated from diarrheal patients in Kolkata, India. PLoS Neglected Tropical Diseases, 8: e2815. doi: 10.1371/journal.pntd.0002815

Pang, B. 2020. Unpublished data. State Key Laboratory of Infectious Disease Prevention and Control, National Institute for Communicable Disease Control and Prevention, Chinese Center for Disease Control and Prevention, Beijing, China.

Pfeffer, C.S. Hite, M. F. \& Oliver, J.D. 2003. Ecology of Vibrio vulnificus in estuarine waters of eastern North Carolina. Applied and Environmental Microbiology, 69: 3526-3531.

Potasman, I., Paz, A. \& Odeh, M. 2002. Infectious outbreaks associated with bivalve shellfish consumption: a worldwide perspective. Clinical Infectious Diseases, 35(8): 921-8.

Powell, A., Baker-Austin, C., Wagley, S., Bayley, A. \& Hartnell, R. 2013. Isolation of pandemic $V$. parahaemolyticus isolated from UK shellfish produce and water. Microbial Ecology, 65: 924-927.

Public Health Agency of Canada. 2020. Publicly available international foodborne outbreak database (PAIFOD). 
Public Health England (PHE). 2021. Unpublished data.

Rippey, S.R. 1994. Infectious diseases associated with molluscan shellfish consumption. Clinical Microbiology Reviews, 7: 419-425.

Ritchie, J.M., Rui, H., Zhou, X., Iida, T., Kodoma, T., Ito, S., Davis, B. M., Bronson, R. T. \& Waldor, M.K. 2012. Inflammation and disintegration of intestinal villi in an experimental model for V. parahaemolyticus-induced diarrhea. PLOS Pathogens, 8(3): e1002593.

Rivera, S., Lugo, T. \& Hazen, T.C. 1989. Autoecology of V. vulnificus and V. parahaemolyticus in tropical waters. Water Research, 23: 923-931.

Rodríguez Iglesias, M. 2020. Unpublished data. Hospital Universitario Puerta del Mar, Cádiz, Spain.

Roig, F. J., Sanjuán, E., Llorens, A. \& Amaro, C. 2010. PilF polymorphism-based PCR to distinguish $V$. vulnificus strains potentially dangerous to public health. Applied and Environmental Microbiology, 76: 1328-1333.

Rosche, T.M., Yano, Y. \& Oliver, J.D. 2005. A rapid and simple PCR analysis indicates there are two subgroups of $V$. vulnificus which correlate with clinical or environmental isolation. Microbiology and Immunology, 49: 381-389.

Saara Salmenlinna. 2020. Unpublished data. National Institute for Health and Welfare, Finland.

Sakazaki, R., Tamura, K., Kato, T., Obara, Y., \& Yamai, S. 1968. Studies on the enteropathogenic, facultatively halophilic bacterium, Vibrio parahaemolyticus. 3. Enteropathogenicity. Japanese Journal of Medical Science and Biology, 21(5): 325-331. (also available from: https://doi.org/10.7883/yoken1952.21.325).

Scaglione, S., Kliethermes, S., Cao, G., Shoham, D., Durazo, R., Luke, A. \& Volk, M.L. 2015. The epidemiology of cirrhosis in the United States: A populationbased study. Journal of Clinical Gastroenterology, 49(8): 690-6.

Scallan, E., Hoekstra, R.M., Angulo, F.J., Tauxe, R.V., Widdowson, M.A., Roy, S.L., Jones, J.L. \& Griffin, P. M. 2011. Foodborne illness acquired in the United States Major pathogens. Emerging Infectious Diseases, 17: 7-15.

Schmucker, D.L. 2005. Agerelated changes in liver structure and function: Implications for disease? Experimental Gerontology, 40(8-9): 650-659. doi: 10.1016/j. exger.2005.06.009

Semenza, J.C., Trinanes, J., Lohr, W., Sudre, B., Löfdahl, M., Martinez-Urtaza, J., Nichols, G.L. \& Rocklöv, J. 2017. Environmental suitability of Vibrio infections in a warming climate: an early warning system. Environmental Health Perspectives, 125: 107004. doi: 10.1289/EHP2198.

Shen, X., Su, Y.-C., Liu, C., Oscar, T. \& DePaola, A. 2019. Efficacy of V. parahaemolyticus (depuration in oysters (Crassostrea gigas). Food Microbiology, 79: 35-40. 
Shen, X., Cai, Y., Liu, C., Liu, W., Hui, Y. \& Su, Y.-C. 2009. Effect of temperature on uptake and survival of $V$. parahaemolyticus in oysters (Crassostrea plicatula). International Journal of Food Microbiology, 136: 129-132.

Spaur, M., Davis, B.J.K., Kivitz, S., DePaola, A., Bowers, J.C., Curriero, F.C. \& Nachman, K.E. 2020. A systematic review of post-harvest interventions for Vibrio parahaemolyticus in raw oysters. Science of the Total Environment, 745: 140795.

Suffredini, E., Cozzi, L., Ciccaglioni, G. \& Croci, L. 2014. Development of a colony hybridization method for the enumeration of total and potentially enteropathogenic Vibrio parahaemolyticus in shellfish. International Journal of Food Microbiology, 186: 22-31. (also available from: https://doi.org/10.1016/j.ijfoodmicro.2014.06.009).

Taylor, M., Cheng, J., Sharma, D., Bitzikos, O., Gustafson, R., Fyfe, M., Greve, R., Murti, M., Stone, J., Honish, L., Mah, V., Punja, N., Hexemer, A., McIntyre, L., Henry, B., Kendall, P., Atkinson, R., Buenaventura, E., Martinez-Perez, A., Galanis, E. \& the Outbreak Invesitigation Team. 2018. Outbreak of Vibrio parahaemolyticus Associated with Consumption of Raw Oysters in Canada, 2015. Foodborne Pathogens and Disease, 15(9): 554-559.

Tomoyasu T. 1992. Development of the immunomagnetic enrichment method selective for Vibrio parahaemolyticus serotype $\mathrm{K}$ and its application to food poisoning study. Applied and Environmental Microbiology, 58(8): 2679-2682. (also available from: https://doi.org/10.1128/AEM.58.8.2679-2682.1992).

United Nations. 2019. World Population Ageing 2019: Highlights. https://www.un.org/en/ development/desa/population/publications/pdf/ageing/WorldPopulationAgeing2019Highlights.pdf

Urquhart, E.A., Jones, S.H., Yu, J.W., Schuster, B.M., Marcinkiewicz, A.L., Whistler C.A. \& Cooper V.S. 2016. Environmental conditions associated with Elevated Vibrio parahaemolyticus concentrations in Great Bay estuary, New Hampshire. PLOS ONE, 11(5): e0155018

USFDA. 2011. Fish and fishery products hazards and controls guidance. Fourth edition, April 2011. http://www.fda.gov/downloads/Food/GuidanceRegulation/ UCM251970.pdf

Xu, F., Gonzalez-Escalona, N., Drees, K.P., Sebra, R.P., Cooper, V.S., Jones, S.H. \& Whistler, C.A. 2017. Parallel evolution of two clades of an Atlantic-endemic pathogenic lineage of $V$. parahaemolyticus by independent acquisition of related pathogenicity islands. Applied and Environmental Microbiology, 83(18): e01168-17. doi: 10.1128/AEM.01168-17.

Smolikova, L.M., Lomov, I.M., Khomenko, T.V., Murnachev, G.P., Kudriakova, T.A., Fetsailova, O.P., Sanamiants, E.M., Makedonova, L.D., Kachkina, G.V. \& Golenishcheva, E.N. 2001. Studies on halophilic vibrios causing a food poisoning outbreak in the city of Vladivostok. Zhurnal Mikrobiologii, Epidemiologii $i$ Immunobiologii, 63: 3-7. 
Vezzulli, L., Brettar, I., Pezzati, E., Reid, P.C., Colwell, R.R., Höfle, M.G. \& Pruzzo, C. 2012. Longterm effects of ocean warming on the prokaryotic community: evidence from the vibrios. ISME Journal, 6(1): 21-30.

Wagatsuma S. 1968. On the medium for haemolytic reaction. Media Circle, 13: 159-162.

Wang, C.Y., Huang, H.W., Hsu, C.P., Shyu, Y.T. \& Yang, B.B. 2013. Inactivation and morphological damage of $V$. parahaemolyticus treated with high hydrostatic pressure. Food Control, 32: 348-353.

Watts, N., Amann, M., Arnell, N., Ayeb-Karlsson, S., Belesova, K., Boykoff, M., Byass, P., Cai, W., Campbell-Lendrum, D., Capstick, S., Chambers, J., Dalin, C., Daly, M., Dasandi, N., Davies, M., Drummond, P., Dubrow, R., Ebi, K. L., Eckelman, M., Ekins, P., Escobar, L.E., Fernandez Montoya, L., Georgeson, L., Graham, H., Haggar, P., Hamilton, I., Hartinger, S., Hess, J., Kelman, I., Kiesewetter, G., Kjellstrom, T., Kniveton, D., Lemke, B., Liu, Y., Lott, M., Lowe, R., Sewe, M.O., Martinez-Urtaza, J., Maslin, M., McAllister, L., McGushin, A., Jankin Mikhaylov, S., Milner, J., Moradi-Lakeh, M., Morrissey, K., Murray, K., Munzert, S., Nilsson, M., Neville, T., Oreszczyn, T., Owfi, F., Pearman, O., Pencheon, D., Phung, D., Pye, S., Quinn, R., Rabbaniha, M., Robinson, E., Rocklöv, J., Semenza. J.C., Sherman, J., Shumake-Guillemot, J., Tabatabaei, M., Taylor, J., Trinanes, J., Wilkinson, P., Costello, A., Gong, P. \& Montgomery, H. 2019. The 2019 report of The Lancet Countdown on health and climate change: ensuring that the health of a child born today is not defined by a changing climate. Lancet, 394: 1836-1878.

World Health Organization (WHO). 2014. Global status report on alcohol and health 2014 ed. (also available from: https://www.who.int/substance_abuse/publications/ alcohol_2014/en/).

Wu, Y., Wen, J., Ma, Y., Ma, X. \& Chen, Y. 2014. Epidemiology of foodborne disease outbreaks caused by V. parahaemolyticus, China, 2003-2008. Food Control, 46: 197-202. (also available from: https://doi.org/10.1016/j. foodcont.2014.05.023).

Ye, M., Huang, Y. \& Chen, H. 2012. Inactivation of Vibrio parahaemolyticus and Vibrio vulnificus in oysters by high-hydrostatic pressure and mild heat. Food Microbiology, 32: 179-184.

Yamazaki, W., Ishibashi, M., Kawahara, R. \& Inoue, K. 2008. Development of a loopmediated isothermal amplification assay for sensitive and rapid detection of Vibrio parahaemolyticus. BMC Microbiology, 8, 163. (also available from: https://doi. org/10.1186/1471-2180-8-163). 

Annexes 


\section{Selected available data on the incidence of $V$. parahaemolyticus infections in}

\section{China}

\begin{tabular}{|c|c|c|c|c|c|c|}
\hline Regions & Period & $\begin{array}{l}\text { No. of cases } \\
\text { (outbreaks) }\end{array}$ & $\begin{array}{l}\text { Attributed } \\
\text { food }\end{array}$ & $\begin{array}{c}\text { tdh / trh presence } \\
\text { (where reported) } \\
\text { (\%) (Note: confirm } \\
\text { all figures are given } \\
\text { in \%) }\end{array}$ & Symptoms & Origin of data \\
\hline \multirow{10}{*}{$\begin{array}{l}\text { South } \\
\text { China }\end{array}$} & 2011 & $367(17)$ & N/A & N/A & diarrhea & Data not published \\
\hline & 2012 & 193(17) & N/A & N/A & diarrhea & Data not published \\
\hline & 2013 & $145(7)$ & N/A & N/A & diarrhea & Data not published \\
\hline & 2014 & $353(27)$ & $N / A$ & N/A & diarrhea & Data not published \\
\hline & 2015 & $143(10)$ & N/A & N/A & diarrhea & Data not published \\
\hline & 2016 & $246(12)$ & $N / A$ & $N / A$ & diarrhea & Data not published \\
\hline & 2017 & $508(26)$ & N/A & N/A & diarrhea & Data not published \\
\hline & 2018 & $371(23)$ & N/A & N/A & diarrhea & Data not published \\
\hline & 2019 & $512(30)$ & N/A & N/A & diarrhea & Data not published \\
\hline & 2020 & $297(21)$ & N/A & $N / A$ & diarrhea & Data not published \\
\hline \multirow{11}{*}{$\begin{array}{l}\text { Central } \\
\text { China }\end{array}$} & 2010 & $62(5)$ & $N / A$ & N/A & diarrhea & Data not published \\
\hline & 2011 & $46(3)$ & $N / A$ & N/A & diarrhea & Data not published \\
\hline & 2012 & $34(3)$ & N/A & N/A & diarrhea & Data not published \\
\hline & 2013 & $8(2)$ & $N / A$ & N/A & diarrhea & Data not published \\
\hline & 2014 & $42(4)$ & N/A & $N / A$ & diarrhea & Data not published \\
\hline & 2015 & $62(4)$ & N/A & N/A & diarrhea & Data not published \\
\hline & 2016 & $41(5)$ & N/A & N/A & diarrhea & Data not published \\
\hline & 2017 & $70(7)$ & N/A & N/A & diarrhea & Data not published \\
\hline & 2018 & $76(6)$ & $N / A$ & N/A & diarrhea & Data not published \\
\hline & 2019 & $147(10)$ & N/A & N/A & diarrhea & Data not published \\
\hline & 2020 & 26(1) & $N / A$ & $N / A$ & diarrhea & Data not published \\
\hline
\end{tabular}




\begin{tabular}{|c|c|c|c|c|c|c|}
\hline Regions & Period & $\begin{array}{l}\text { No. of cases } \\
\text { (outbreaks) }\end{array}$ & $\begin{array}{l}\text { Attributed } \\
\text { food }\end{array}$ & $\begin{array}{c}\text { tdh / trh presence } \\
\text { (where reported) } \\
\text { (\%) (Note: confirm } \\
\text { all figures are given } \\
\text { in \%) }\end{array}$ & Symptoms & Origin of data \\
\hline \multirow{11}{*}{ East China } & 2010 & NA & N/A & N/A & diarrhea & Data not published \\
\hline & 2011 & NA & N/A & N/A & diarrhea & Data not published \\
\hline & 2012 & $32(2)$ & N/A & N/A & diarrhea & Data not published \\
\hline & 2013 & $16(1)$ & N/A & N/A & diarrhea & Data not published \\
\hline & 2014 & $77 /(1)$ & N/A & N/A & diarrhea & Data not published \\
\hline & 2015 & $26(4)$ & N/A & N/A & diarrhea & Data not published \\
\hline & 2016 & 194(23) & N/A & N/A & diarrhea & Data not published \\
\hline & 2017 & $250(24)$ & $\mathrm{N} / \mathrm{A}$ & N/A & diarrhea & Data not published \\
\hline & 2018 & $422(31)$ & N/A & N/A & diarrhea & Data not published \\
\hline & 2019 & $294(34)$ & N/A & N/A & diarrhea & Data not published \\
\hline & 2020 & $26(2)$ & N/A & N/A & diarrhea & Data not published \\
\hline \multirow{11}{*}{$\begin{array}{l}\text { Southwest } \\
\text { China }\end{array}$} & 2010 & 0 & N/A & N/A & diarrhea & Data not published \\
\hline & 2011 & 1 & N/A & N/A & diarrhea & Data not published \\
\hline & 2012 & 4 & N/A & N/A & diarrhea & Data not published \\
\hline & 2013 & 3 & N/A & N/A & diarrhea & Data not published \\
\hline & 2014 & 2 & N/A & N/A & diarrhea & Data not published \\
\hline & 2015 & 6 & N/A & $\mathrm{N} / \mathrm{A}$ & diarrhea & Data not published \\
\hline & 2016 & 13 & N/A & N/A & diarrhea & Data not published \\
\hline & 2017 & 17 & $\mathrm{~N} / \mathrm{A}$ & N/A & diarrhea & Data not published \\
\hline & 2018 & 5 & N/A & N/A & diarrhea & Data not published \\
\hline & 2019 & 8 & N/A & N/A & diarrhea & Data not published \\
\hline & 2020 & 3 & $\mathrm{~N} / \mathrm{A}$ & N/A & diarrhea & Data not published \\
\hline
\end{tabular}




\section{FAO/WHO Microbiological Risk Assessment Series}

1 Risk assessments of Salmonella in eggs and broiler chickens: Interpretative Summary, 2002

2 Risk assessments of Salmonella in eggs and broiler chickens, 2002

3 Hazard characterization for pathogens in food and water: Guidelines, 2003

4 Risk assessment of Listeria monocytogenes in ready-to-eat foods: Interpretative Summary, 2004

5 Risk assessment of Listeria monocytogenes in ready-to-eat foods: Technical Report, 2004

6 Enterobacter sakazakii and microorganisms in powdered infant formula: Meeting Report, 2004

7 Exposure assessment of microbiological hazards in food: Guidelines, 2008

8 Risk assessment of Vibrio vulnificus in raw oysters: Interpretative Summary and Technical Report, 2005

9 Risk assessment of choleragenic Vibrio cholerae 01 and 0139 in warm-water shrimp in international trade: Interpretative Summary and Technical Report, 2005

10 Enterobacter sakazakii and Salmonella in powdered infant formula: Meeting Report, 2006

11 Risk assessment of Campylobacter spp. in broiler chickens: Interpretative Summary, 2008

12 Risk assessment of Campylobacter spp. in broiler chickens: Technical Report, 2008

13 Viruses in food: Scientific Advice to Support Risk Management Activities: Meeting Report, 2008

14 Microbiological hazards in fresh leafy vegetables and herbs: Meeting Report, 2008

15 Enterobacter sakazakii (Cronobacter spp.) in powdered follow-up formula: Meeting Report, 2008

16 Risk assessment of Vibrio parahaemolyticus in seafood: Interpretative Summary and Technical Report, 2011

17 Risk characterization of microbiological hazards in food: Guidelines, 2009.

18 Enterohaemorragic Escherichia coli in beef and beef products: Approaches for the provision of scientific advice, Meeting Report, 2010

19 Salmonella and Campylobacter in chicken meat: Meeting Report, 2009 
20 Risk assessment tools for Vibrio parahaemolyticus and Vibrio vulnificus associated with seafood: Meeting Report, 2020

21 Salmonella spp. In bivalve molluscs: Risk Assessment and Meeting Report, In press

22 Selection and application of methods for the detection and enumeration of human pathogenic halophilic Vibrio spp. in seafood: Guidance, 2016

23 Multicriteria-based ranking for risk management of food-borne parasites, 2014

24 Statistical aspects of microbiological criteria related to foods: A risk managers guide, 2016

25 Risk-based examples and approach for control of Trichinella spp. and Taenia saginata in meat: Meeting Report, 2020

26 Ranking of low moisture foods in support of microbiological risk management: Meeting Report and Systematic Review, In press

27 Microbiological hazards associated with spices and dried aromatic herbs: Meeting Report, In press

28 Microbial safety of lipid based ready-to-use foods for management of moderate acute malnutrition and severe acute malnutrition: First meeting report, 2016

29 Microbial safety of lipid based ready-to-use foods for management of moderate acute malnutrition and severe acute malnutrition: Second meeting report, 2021

30 Interventions for the control of non-typhoidal Salmonella spp. in beef and pork: Meeting Report and Systematic Review, 2016

31 Shiga toxin-producing Escherichia coli (STEC) and food: attribution, characterization, and monitoring, 2018

32 Attributing illness caused by Shiga toxin-producing Escherichia coli (STEC) to specific foods, 2019

33 Safety and quality of water used in food production and processing, 2019

34 Foodborne antimicrobial resistance: role of the environment, crops and biocides, 2019.

35 Advances in science and risk assessment tools for Vibrio parahaemolyticus and V. vulnificus associated with seafood, 2021. 
Globally, the Vibrio parahaemolyticus and Vibrio vulnificus represent important human pathogens associated with the consumption of seafood. In response to the requests for scientific advice from Codex Committee on Food Hygiene (CCFH), risk assessments for the pathogens $V$. vulnificus, $V$. cholerae, $\mathrm{V}$. parahaemolyticus and guidance on methods for the detection of Vibrio spp. with seafood have been conducted and published previously by JEMRA. In order to provide an update on the state-of-the-art advice regarding risk assessment for $V$. parahaemolyticus and $V$. vulnificus in seafood, an expert meeting was convened.

Several critical developments in the last decade were subsequently noted by the expert working group: 1) The emergence of highly pathogenic strains; 2) In response to climate change, there has been a significant geographical spread regarding when and where these seafood-associated Vibrio infections; 3) Demographic considerations are very important; 4) A range of new approaches for best practice; and 5) A range of new methods, such as those utilising genomics and satellite imagery. This report describes the output of that expert meeting.

Food Systems and Food Safety - Economic and Social Development jemra@fao.org http://www.fao.org/food-safety

Food and Agriculture Organization of the United Nations Viale delle Terme di Caracalla 00153 Rome, Italy

Department of Nutrition and Food Safety jemra@who.int https://www.who.int/health-topics/food-safety/ World Health Organization 20 Avenue Appia 1211 Geneva 27, Switzerland

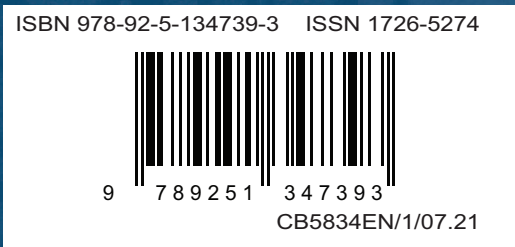

